OPEN ACCESS

Edited by:

Swasti Tiwari,

Sanjay Gandhi Post Graduate Institute of Medical Sciences (SGPGI), India

Reviewed by:

Jun Wada,

Okayama University, Japan

Rashmi Tupe,

Symbiosis International

University, India

*Correspondence:

Isha Sharma

isha.sharma1@northwestern.edu

Yashpal S. Kanwar

y-kanwar@northwestern.edu

Specialty section:

This article was submitted to

Nephrology,

a section of the journal

Frontiers in Medicine

Received: 17 March 2021

Accepted: 28 May 2021

Published: 29 June 2021

Citation:

Sharma I, Liao $Y$, Zheng $X$ and Kanwar YS (2021) New Pandemic: Obesity and Associated Nephropathy.

Front. Med. 8:673556.

doi: 10.3389/fmed.2021.673556

\section{New Pandemic: Obesity and Associated Nephropathy}

\author{
Isha Sharma ${ }^{1 *}$, Yingjun Liao ${ }^{1,2}$, Xiaoping Zheng ${ }^{1,3}$ and Yashpal S. Kanwar ${ }^{1 *}$ \\ ${ }^{1}$ Departments of Pathology and Medicine, Northwestern University, Chicago, IL, United States, ${ }^{2}$ Department of Nephrology, \\ Second Xiangya Hospital, Central South University, Changsha, China, ${ }^{3}$ Department of Urology, Third Xiangya Hospital, \\ Central South University, Changsha, China
}

Incidence of obesity related renal disorders have increased 10-folds in recent years. One of the consequences of obesity is an increased glomerular filtration rate (GFR) that leads to the enlargement of the renal glomerulus, i.e., glomerulomegaly. This heightened hyper-filtration in the setting of type 2 diabetes irreparably damages the kidney and leads to progression of end stage renal disease (ESRD). The patients suffering from type 2 diabetes have progressive proteinuria, and eventually one third of them develop chronic kidney disease (CKD) and ESRD. For ameliorating the progression of CKD, inhibitors of renin angiotensin aldosterone system (RAAS) seemed to be effective, but on a short-term basis only. Long term and stable treatment strategies like weight loss via restricted or hypo-caloric diet or bariatric surgery have yielded better promising results in terms of amelioration of proteinuria and maintenance of normal GFR. Body mass index (BMI) is considered as a traditional marker for the onset of obesity, but apparently, it is not a reliable indicator, and thus there is a need for more precise evaluation of regional fat distribution and amount of muscle mass. With respect to the pathogenesis, recent investigations have suggested perturbation in fatty acid and cholesterol metabolism as the critical mediators in ectopic renal lipid accumulation associated with inflammation, increased generation of ROS, RAAS activation and consequential tubulo-interstitial injury. This review summarizes the renewed approaches for the obesity assessment and evaluation of the pathogenesis of CKD, altered renal hemodynamics and potential therapeutic targets.

Keywords: obesity, kidney, hyperlipidemia, inflammation, oxidant stress, fibrosis

\section{INTRODUCTION}

"Diabesity" is a new term, often used globally, to reflect the status of coexisting diabetes and obesity, especially those in the aging population. It has emerged as the major cause of chronic kidney disease (CKD) (1-7). World health organization (WHO) data suggest that since 1975 worldwide obesity $\left(\mathrm{BMI} \geq 30 \mathrm{~kg} / \mathrm{m}^{2}\right.$ ) has tripled. According to 2016 statistics over 1.9 billion adults, i.e., 18 years of age and older, were obese, and nearly $39 \%$ of them were overweight. Among the obese population about $13 \%$ were men and $15 \%$ and were women, respectively, across diverse ethnicities. Wide ethnic disparities were found for the prevalence of obesity: Whites (22.0\%), Latinos (33.6\%), African Americans (36.1\%), and Asians (9.8\%) (8). In recent years, childhood obesity has also become more prevalent, and nearly 38 million children under the age of five have been found to be obese worldwide. Moreover, over 340 million children and adolescents, between the ages of 5-19, were 
regarded as obese worldwide. In view of the increasing incidence of obesity it is estimated that by the year 2030 more than $50 \%$ of the USA population will be obese (9). Sadly enough, this epidemic of obesity and its associated complications would cause a substantial socioeconomic burden to various countries. In addition, increase in the incidence of obesity has led to some of the associated systemic chronic disorders; such as nephropathy that is characterized by proteinuria, subclinical inflammation, progressive fibrosis and ultimately resulting in the decline of renal functions. In general, obese individuals are more adversely affected globally than those with normal- or under-weight. To gage characteristics of obesity, elevated BMI is used as one of the major parameters (10), however, more ancillary stringent methods for the assessment and management of obesity are needed. This review focusses on recent developments in the assessment of obesity, its pathogenesis and complications, including perturbed fatty acid metabolism, altered renal hemodynamics and development of CKD. Lastly, potential therapeutic targets, which can be used for the amelioration of obesity and its associated renal complications are discussed.

\section{OBESITY INDUCED DIABETIC NEPHROPATHY}

\section{Obesity: Definition and Epidemiologic Analysis}

According WHO guidelines individuals with BMI between 20 and $25 \mathrm{~kg} / \mathrm{m}^{2}$ are considered normal, and having BMI between 25 and $30 \mathrm{~kg} / \mathrm{m}^{2}$ as overweight, and with $>30 \mathrm{~kg} / \mathrm{m}^{2}$ are regarded as obese. Based on the BMI, obesity itself has been classified into three grades: grade 1, 2, 3 with BMI being $30-34.9 \mathrm{~kg} / \mathrm{m}^{2}$, $35-39.9 \mathrm{~kg} / \mathrm{m}^{2}$, and $\geq 40 \mathrm{~kg} / \mathrm{m}^{2}$, respectively $(11,12)$. A study was conducted at the Columbia University correlating high BMI and CKD over a span of three decades, and it pointed toward a gradually increasing incidence of the latter, i.e., CKD, from $0.2 \%$ in $1986-1990$ to $2 \%$ in $1996-2000$, which further increased to $2.7 \%$ in $2001-2015$ (12). The data also indicated that $56 \%$ of the patients had proteinuria, while $44 \%$ had both proteinuria and a decline in renal functions $(11,12)$. Although this correlation may be applicable to Western population, it should be noted that among the Asians even people with lower BMI have the potential risk of developing CKD (12). Here, another enigmatic issue is that although BMI is easy to calculate, it is not an ideal predictor of $\mathrm{CKD}$, and it may not accurately reflect the spatial distribution of fat mass with respect to obesity $(13,14)$. Moreover, at times, it is hard to distinguish between BMI of an individual with heavy musculature and one having ample subcutaneous fat; ironically both may have the same BMI. Certainly, the one with excessive amount of visceral fat may have the higher risk for the development of CKD (15). As an alternative to traditional BMI measurement, waist circumference (WC) and waist hip ratio (WHR) estimates would be more accurate reflective of the extent of visceral fat depots. In this regard, it is known that the incidence of obesity associated diabetes or CKD the incidence increases with a WC $>102 \mathrm{~cm}$ and WHR of 0.9 for men, and $>88 \mathrm{~cm}$ and
0.8 for women (15). Also, WHR and skin fold thickness are better predicators of CKD in obesity compared to BMI (16).

\section{Overview of Obesity and Associated CKD}

In recent years, obesity has become a considerable health problem that has affected people of all races and ethnicities. Even if society becomes aware of this huge socioeconomic problem, it still may take decades to revert the increasing incidence of obesity to the prevailing levels of 30-40 years ago. There was a misconception that the rapid increase in obesity is observed only in well-developed nations, such as Europe and USA (17). On the contrary, countries with low and middle-income strata are experiencing a similar dilemma. For instance, recent data indicate that the prevalence of obesity and CKD have markedly increased in countries like China (18), India (19), and Brazil (20). Customarily, individuals with poor knowledge of nutrition and with substandard living conditions are at a greater risk for developing obesity and its related complications. Clinical data suggest that obesity and obesity associated glomerulopathy (ORG) are potential risk factors for the development and progression of CKD. It is worth mentioning here that the data of retrospective clinical study on renal biopsies of 620 diabetic patients suggested a high proportion of them, i.e., $33 \%$, had diabetic nephropathy, and in addition $27 \%$ had diabetic nephropathy with superimposed "non-diabetic renal disease" $(12,21)$. Before discussing the pathogenesis of CKD comprehensively, a general overview of the pathophysiology of obesity may be worthwhile considering. It is a complex process with a multitude of inter-related facets, including genetic predisposition, individual dietary habits and physical inactivity, and environmental and other ancillary factors (Figure 1). First, until recently, 150 gene loci have been linked to the development of obesity and type 2 diabetes (22). Fat-mass and obesityassociated gene (FTO) polymorphism, localized to chromosome 16 , has been described to be associated with $\sim 7 \%$ phenotypic variability in BMI (23). Although much advancements have been made in identifying the epigenetic markers of obesity, there is still a lack of information regarding tissue specific epigenetic markers of obesity (24). Here, a thorough understanding of energy balance/imbalance is needed since it is one of the key factors responsible for obesity. Considerable intake of sucrose and fructose over a long period certainly increases the risk of developing metabolic syndrome with consequential CKD (25, 26). Ironically, the gratuitous marketing strategy by the food industry of enriching certain products with high fructose (27), such as corn syrup, with high glycemic index is not very helpful; rather it exacerbates the epidemic of obesity, thereby increasing the incidence of a number of metabolic associated disorders, e.g., type 2 diabetes, hypertension, gout and CKD $(26,28)$. Moreover, a sedentary lifestyle with physical inactivity further contribute to the development of obesity and its related disorders (29). Other factors, which could serve as conduits for the onset of obesity and subsequent CKD may include, neurocognitive factors (30), psychological stress (31), genetic mutations (32), altered gut microbiota (33) and adenoviral infections, e.g., adeno virus36 (AD-36) (34). Ancillary background factor(s) responsible for the development of $\mathrm{CKD}$ may include reduction in the nephron 


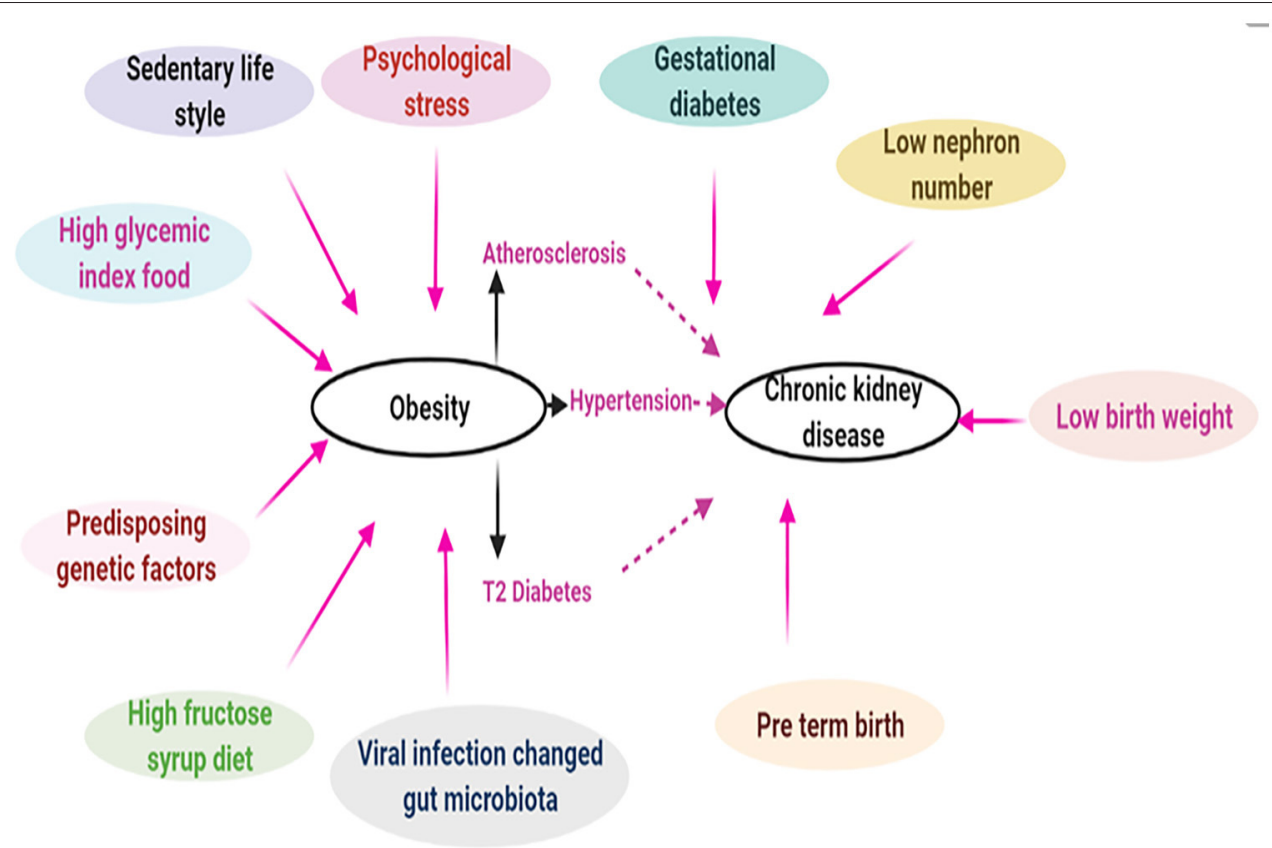

FIGURE 1 | Complex intricate relationship between obesity and chronic kidney disease. Pathophysiology of obesity is very complex which may include genetic (epigenetic) and environmental factors. Obesity driven hypertension, atherosclerosis, and T2 diabetes may lead to chronic kidney disease. In addition, other ancillary factors like gestational diabetes, low nephron number can also contribute to CKD [Adapted from Stenvinkel et al. (2)].

number (35). In this regard, children with prematurity and intrauterine growth retardation of the fetus are also considered as risk factors for the onset of CKD following development of hypertension and T2DM in later life. Indeed, epidemiological studies support the data that a combination of low birth weight, malnourished childhood, and adolescent obesity would augment the prevalence of CKD (36).

\section{Hyperlipidemia Induced Renal Injury}

The extent of ectopic lipid accumulation positively correlates very well with insulin resistance compared to any other predicators of obesity onset, i.e., BMI, WC, or WHR (37). Such lipid accumulation expectedly adverse the pathobiology of renal cells. For instance, with the excessive lipid accumulation the renal glomerular mesangial cells, and at times the endothelial cells, undergo foamy transformation via various receptor-mediated mechanisms with a multitude of adverse downstream events (38). In this regard, in vitro studies have shown progressive loss of contractile functions of mesangial cells with lipid accumulation. In the event where there is a concomitant subclinical inflammation, such as in diabetes, the lipid accumulation would accentuate, and which may lead to LDL-receptor dysregulation and disruption in feedback regulation and foamy transformation of intrinsic renal glomerular cells (podocytes, endothelial, and mesangial cells) as well as accumulation of triglycerides (39). The latter may accentuate dysfunctions of the glomerular cells, altered hemodynamics, increased nitric oxide (NO) generation, augmented inflammation and subsequent albuminuria $(39,40)$.
The hydrolysis of triglycerides leads to formation of glycerol and non-esterified free fatty acids (NEFA). Normally, a majority of the NEFA/FFA are albumin bound and induce macropinocytosis in podocytes, which would be reflective of their functional integrity $(40,41)$. Conversely, free fatty acids (FFA) are likely to induce renal cellular damage to the podocytes with consequential albuminuria. Incidentally, ratio of free serum NEFA to albumin bound NEFA increases in parallel with angiopoietin-related protein 4 (ANGPTL4), the latter inhibits lipoprotein lipase leading to further triglyceridemia and inducing a proteinuric response $(40,41)$. Onset of hyperlipidemia and albuminuria in obesity is a self-perpetuating loop (Figure 2), as hypothesized by Moorhead and others, which state that lipid accumulation and infliction of renal injury are mutually interdependent processes enhancing the activity of each other $(42,43)$. Increased fat deposition not only leads to a compromise in the functionality of mesangial cell and podocytes, but it also initiates a series of downstream cellular events with activation of TGF- $\beta / \mathrm{Smad} 3$ signaling pathway, which ultimately lead to renal fibrosis. The renal fibrosis encompasses both glomerulosclerosis and tubulo-interstitial fibrosis. With respect to the latter, proximal tubules, heavily consume NEFA that are needed for meeting the demands of energy-dependent tubular transport processes. However, in states of obesity there may be availability of excessive amounts of NEFA which are likely to accumulate in the cytosolic lipid droplets as triglycerides $(42,44)$. This amassing would eventually perturb other cellular processes, including fatty acid oxidation. Here, although it has been reported that obesity associated renal damage is 


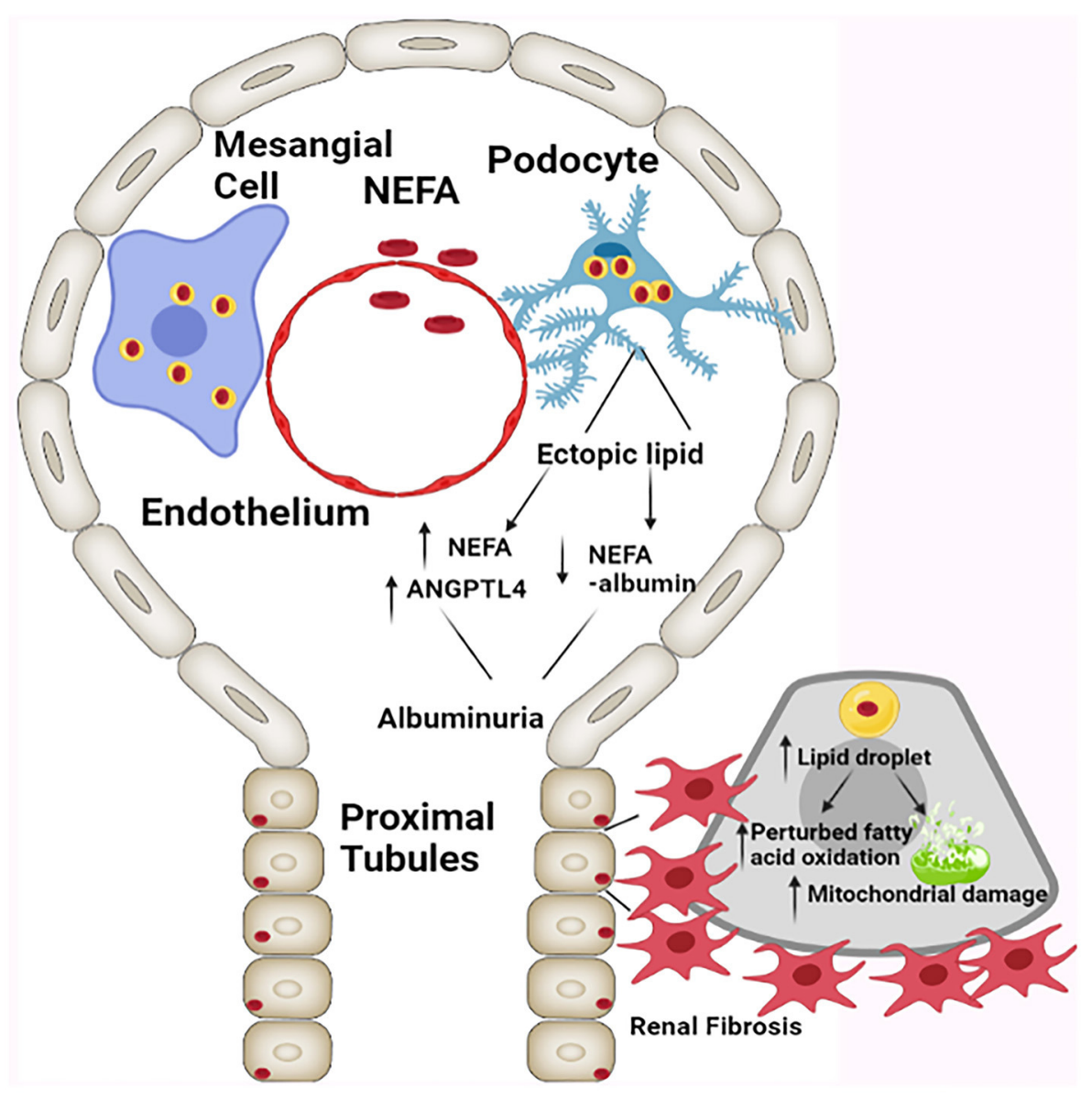

FIGURE 2 | Schematic presentation depicting the effect of ectopic cellular lipid accumulation resulting in the compromise of glomerular and tubular integrity, and causing albuminuria, altered mitochondrial dynamics, and tubulo-interstitial fibrosis. NEFA: Non-esterified fatty acids, ANGPTL4: Angiopoietin-related protein 4 [Adapted from D'Agati et al. (12)].

linked to perturbed fatty acid metabolism (45), the question arises as to how these cellular perturbations eventually cause tubulo-interstitial fibrosis. Supporting the above-mentioned notion, deep sequencing analysis in patients with CKD suggested impairment in fatty acid oxidation and activation of pathways related to inflammatory processes (45). The proximal renal tubular epithelia are mainly dependent on fatty acid oxidation (FAO) for their energy demand. Apparently, it is the FAO which is diminished in chronic kidney diseases as a result there would be an increased accumulation of fatty acid, thus causing dyslipidemia. Some of the ancillary molecules that are involved in the activation of pathways relevant to inflammation and perturbed fatty acid oxidation conceivably include TGF- $\beta$ and SMAD. The TGF- $\beta$, a cytokine that is upstream of SMAD, and the latter binds to the regulatory region of PPAR $\gamma$ co-activator $-1 \alpha(\mathrm{PGC} 1 \alpha)$ promoter, as suggested by Kang et al. (45). The $\mathrm{PGC} 1 \alpha$ is a transcription factor that besides being a master regulator of mitochondrial biogenesis, it is also known to induce the expression of carnitine palmitoyltransferase (CPT1), a rate limiting enzyme for $\beta$-oxidation of fatty acids. Thus, it seems that TGF $\beta$-SMAD-PGC1 $\alpha$ axis is an important route via which the FAO is regulated with conceivably modulating the pathways relevant to the inflammatory processes. This being the case it is likely that TGF- $\beta / \mathrm{Smad} 3$ pathway may impair fatty acid oxidation by decreasing the transcriptional expression of PGC1- $\alpha$. In addition, it should be noted that there are certain other molecules which are involved in impaired fatty acid oxidation like, liver kinase beta $1(\operatorname{Lk} \beta 1)$ and AMP activated protein kinase (AMPK). These would be additional signaling molecules involved in the activation of pathways leading to inflammation. Interestingly, palmitate treated cells, comparable to fatty acid accumulation, showed an increased expression of Smad3, which results in negative regulation of PGC1- $\alpha$, and thereby resulting in mitochondrial injury (46). In support of this notion, it has been shown that obesity-induced mitochondrial injury is ameliorated considerably in Smad3 deficient mice. Accumulation of lipids in renal cells has been linked to insulin resistance, and insulin signaling has a prime importance in proximal tubular epithelial cells $(12,47)$. In a murine model, deletion of insulin receptor (IR) in proximal tubules has elevated 
hyperglycemia, conceivably because of increased regional renal gluconeogenesis, where glucose could be derived from noncarbohydrate sources, e.g., renal tubular lipids or triglycerides $(12,47)$. Apparently, perturbed renal glucose absorption is also observed in diabetic state because of the increased activity of glucose transporters. For instance, SGLT2 handles normally $\sim 80 \%$ of the filtered glucose and other $\sim 20 \%$ is derived from endogenous sources generated via regional gluconeogenesis (48). In diabetic state, $\sim 40 \%$ increase in renal gluconeogenesis has been reported (49), while at the same time SGLT2 mRNA expression increases by $\sim 36 \%$ in diabetic state to handle the additional load by the proximal tubular epithelia (50). Overall, total glucose production in the kidney increases in T2D by $\sim 150 \%$ leading to glycosuria, however, the exact percentage of the total glucose handled by SGLT2 in such states is not known (48). Interestingly the renal tubular cells in diabetic state exert a compensatory increase in TmG (transport maximum glucose reabsorption) and renal threshold to handle the excess glucose (48). Like the adaptive processes operative in the liver, insulin is known to decrease renal gluconeogenesis as well (12). Overall it seems that in obesity induced T2DM proximal tubules as well-contribute to hyperglycemia via accentuated gluconeogenesis, and this notion is well-summarized by Meyer et al. (51).

In addition, it may be worth comparing the impact of deposition of saturated vs. unsaturated fatty acid in the progression of CKD. As discussed above, within the kidney, specifically in podocytes, mesangial cells and proximal tubules, and influxed macrophages, ectopic lipid accumulation leads to local inflammation, oxidant stress, mitochondrial dysfunctions and eventual fibrosis. In this regard, the fatty acids, in particular the "saturated ones," contribute significantly toward the onset and progression of CKD. In diabetic nephropathy (DN), accumulation of ectopic lipid and lipid intermediates, like palmitate, ceramide, saturated NEFA, derived from other sources, can deposit in renal parenchyma. The main components of deposited lipid droplets in the renal parenchyma include diacyglycerols, fatty acyl-CoA, ceramides, and sphingolipids. This accumulation of "saturated fatty acids" or intermediaries, as described above, leads to the activation of protein kinase $\mathrm{C}$ (PKC) and via series of downstream events lead to mitochondrial dysfunction in the kidney $(52,53)$. In addition, lipotoxic effects of palmitic acid have been observed in proximal tubules via downregulation of stearoyl-CoA desaturase-1 (SCD-1). The latter is a key enzyme involved in the pathogenesis of lipotoxicityinduced damage to the kidney, since these lipids in a saturated state would have prolonged exposure to renal cells (54). While, overexpression of SCD-1 is known to attenuate fatty acid-mediated cell toxicity (55). On the contrary, in states of progressive $\mathrm{CKD}$, there is a substantial decrease in polyunsaturated fatty acids (PUFAs). Supplementation of Omega-3 PUFA is known to exert substantial renal therapeutic effects, since it would diminish renal lipid accumulation via dampening the Sterol regulatory element binding proteins1 (SREBP-1) mediated downstream signaling related to lipogenesis (56).

\section{ABNORMAL LIPID METABOLISM ASSOCIATED CHANGES IN CKD \\ Perturbed Fatty Acids and Triacylglyceride Metabolism}

Lipids are an important contributor to kidney pathobiology, and $\sim 50 \%$ of the lipids in renal cells are phospholipids. Out of the remaining $50 \%$ nearly $20 \%$ are triglycerides and $10 \%$ are free fatty acids. The kidney is a dynamic organ with high a ATP demand. Since the proximal tubules have a low glycolytic potential fatty acid oxidation contributes to two third of the oxygen used by these cells. Most of the fatty acids in plasma are bound to albumin, and it is the free fatty acids (FFA), which are used by proximal tubules as a fuel. The process of transport of FFA is primarily mediated via a transport protein, known as fatty acid translocase (CD36) (57-59). In addition, apical brush border of proximal tubules also contributes toward FFA uptake. Eventually, imbalance between fatty acid oxidation and its synthesis or increased uptake via CD36 leads to accentuated triacylglyceride accumulation (57).

SREBPs are the master regulator of fatty acid and triacylglyceride synthesis $(58,60)$. Mice subjected to high fat diet (HFD) showed an increased expression of SREBP-1, and it is associated with increased accumulation of lipids in renal proximal tubules (Figure 3) (61). Investigations conducted using SREBP-1 transgenic mice suggested that its overexpression leads to increased lipid deposition and chronic kidney disease (CKD). Increased expression of SREBP adversely affect the pathobiology of the mesangium, and influx of inflammatory cells, oxidant stress, and associated increased expression of TGF- $\beta$ and VEGF. Consequentially there would be an increased expression of extracellular matrix (ECM) proteins leading to glomerulosclerosis, tubulo-interstitial fibrosis with a compromise in renal functions and eventually proteinuria (62). Increased expression of SREBP-1 leads to an accentuated levels of pro-inflammatory cytokines (TNF- $\alpha$, IL- $1 \beta$, interferon- $\gamma$ ). The SREBP-1 has also been found to promote the acute inflammatory responses by regulating the genes involved in the production of active IL-1 $\beta$. In addition, SREBP-1 not only regulates genes involved in lipid metabolism in macrophages, it also activates the expression of core inflammasome NLRP1a via directly binding to its promoter (63). Hence, elevated SREBP expression increases inflammatory responses, and this results in a vicious cycle of fatty acid accumulation, heightened inflammation and oxidative stress. However, besides HFD, hyperglycemia, saturated fatty acid and oxidized lipids, vasoactive peptides like angiotensin II can also increase SREBP-1 levels, resulting in an accentuated TGF- $\beta /$ Smad signaling and eventually renal fibrosis $(58,64)$. In support of the above studies are the experiments with SREBP-1 knockout mice, which showed minimal obesity associated renal defects (65).

\section{Perturbed Cholesterol Metabolism}

Imbalance in cholesterol synthesis and its degradation or increased cholesterol uptake and its decreased efflux leads to an accentuated accumulation of cholesterol. Unlike SREBP1 , SREBP-2 is a regulator of cholesterol metabolism $(66,67)$. 


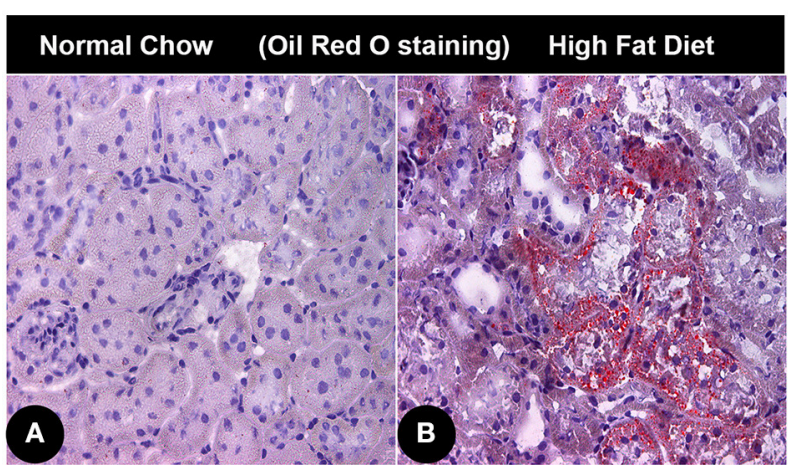

FIGURE 3 | Lipid accumulation in renal cortical tissue of mice with obesity associated diabetic nephropathy. (A) Photomicrograph showing Oil red $\mathrm{O}$ staining in renal cortical tissue of normal control mice. (B) Oil red $O$ stained photomicrograph of renal cortical tissue from an obese mice administered with high fat diet.

Investigations conducted on mice with HFD induced obesity suggest that increased expression of SREBP-2 is intricately associated with cholesterol deposition in renal cells as well as impaired kidney functions $(68-70)$. With the onset of obesity, diabetes or aging, excessive deposition of cholesterol is indicative of increased expression of SREBP-2. Literature data suggest that pro-inflammatory cytokines compromise the functionality of SREBP cleavage-activating protein-SREBP-2Low density lipoprotein (SCAP-SREBP-2-LDL) receptor, and this leads to perturbations in the 3-hydroxy-3-methylglutaryl-CoA reductase pathway (71). Besides these functional perturbations, it should be noted that oxidant stress in obesity also leads to an increased endoplasmic reticulum stress (ER stress), which results in an enhanced release of SREBP-2 from ER (72). Interestingly, it has been reported that advanced glycation end products (AGEs) via oxidant stress lead to random translocation of ER SCAP to Golgi to undergo glycosylation which may lead to activation of SREBP-2, increased cholesterol synthesis and conceivably impaired renal functions (69).

\section{Altered High-Density Lipoprotein in Renal Disorders}

Under normal circumstances HDL protects organ tissue damage against systemic inflammation via removing oxidized lipids from low density lipoprotein (LDL), intermediate density lipoprotein (IDL) and very low density lipoprotein (VLDL). Hyperlipidemia associated nephrotic syndrome is generally characterized by low HDL levels, which at times may be within normal limits (73). However, HDL cholesterol: total cholesterol ratio is reduced in these patients as compared to healthy individuals (74). HDL cholesterol levels are also dramatically reduced in patients with progressive CKD and ESRD. Patient with ESRD have increased levels of oxidized HDL, which exert pro-inflammatory effects, and they bind to large amounts of albumin, phospholipase A2 and serum amyloid A1, and this apparently leads to a compromised HDL functionality (75). One can conceivably deduce that increasing HDL concentration will have potential benefits in ameliorating progression of CKD.
Apparently increasing HDL plasma concentration does not reverse advanced CKD. It is actually not the quantity but the quality of HDL particles, which determines its therapeutic potential. It has been noted that HDL particle composition in advanced CKD is abnormal (depletion of large buoyant HDL and enrichment of small dense HDL) (76). In advanced CKD, kidney has fast catabolism of Apo-A1, which means low quality HDL. These low quality HDLs have greater pro-inflammatory effect than the therapeutic ones. Their activity is impaired possibly because of reduced activity of HDL-associated enzymes, such as paraoxonase 1 (PON1), nitric oxide (NO) synthase (NOS) and lecithin-cholesterol acyltransferase (LCAT) $(77,78)$. In addition, ratio of cholesterol ester-poor HDL3 to cholesterol ester-rich HDL2 is perturbed in patients with advanced CKD (78). The underlying mechanism responsible for the abovementioned abnormalities in HDL metabolism and structurefunctional perturbation are mediated via HDL-impaired reverse cholesterol transport system. The impairment in these biological processes also perturbs HDL anti-inflammatory activity (78).

Patients undergoing hemodialysis have marked reduced ability of $\mathrm{HDL}$ in removing cholesterol from lipid laced macrophage via ATP-binding cassette transporter (ABCA1 ), as compared to healthy individuals (78). Irrespective of up-regulation of ABCA-1, rat renal cells display increased accumulation of lipids in 5/6 nephrectomy mode (71). These enigmatic findings rule out the potential role of ABCA-1 in the dysfunctions of HDL structure and reversal of cholesterol transport in advanced form of CKD. However, continuous oxidative damage of ApoA-1 in CKD diminishes the binding affinity of HDL to the ABCA-1 transporter. This leads to an imbalance in HDL mediated cholesterol efflux. These altered cellular processes leads to defective HDL maturation, impaired reverse cholesterol transport and accentuated atherosclerosis in advanced CKD. Malnourished patient suffering from ESRD have hypoalbuminaemia and also have reduced HDL cholesterol levels, which is mainly because of restricted transfer of albuminbound cholesterol to HDL (79).

Advanced CKD and ESRD not only have HDL deficiency and disrupted reverse cholesterol transport, but also have impaired antioxidant potential of HDL. Patients on hemodialysis also have marked reduction in HDL antioxidant capacity (80). Reduced levels of paraoxnase-1 (PON1) and glutathione peroxidase (GPX) are responsible for reduced anti-inflammatory or -oxidant activity of $\operatorname{HDL}(78,80,81)$. Impairment in HDL levels in patients undergoing hemodialysis can potentially activate generation of inflammatory cytokines (TNF- $\alpha$, IL-6, and IL-1 $\beta$ ) systemically. Also, increased levels of serum amyloid A1 in patients with ESRD potentiate pro-inflammatory response by impairing the HDL functionality. Incidentally, in healthy controls, HDL is known to cause efflux of endotoxin and serum Amyloid A1 from the blood circulation and minimizes the inflammation since the latter increases the generation and release of proinflammatory cytokines $(5,82,83)$. That means HDL antiinflammatory property and the activity of serum amyloid A1 have inverse relationship with each other. Finally, it is wellknown that oxidant stress mediated inflammation because of altered functionality of HDL contribute to pathogenesis of kidney disease. Thus, the systemic oxidant stress and inflammation can 
be regarded as the major drivers of HDL dysfunctions, resulting in subsequent reduction of its anti-inflammatory and antioxidant properties $(84,85)$.

\section{Obesity Mediated Inflammation and CKD}

Endotoxemia is prevalent in $\mathrm{CKD}$, and this contributes to aggravated systemic inflammation (86). Moreover, it has been suggested that endotoxemia induced alterations in gut microbiome may also contribute to inflammation (87). As alluded above, normally HDL strongly binds to endotoxin and disposes them via hepatic route, thus dampening the inflammatory response. HDL deficiency seems to be a prominent factor in aggravating obesity mediated renal changes, as it contributes toward endotoxemia and systemic inflammation that further worsens outcome with microbial infections. Systemic and chronic inflammation are considered as major the factors in triggering CKD in obesity. Mounting amount of data suggest that chronic low-grade inflammation is the dominating feature in this scenario. At times, this could lead to worsening of infections and eventual demise of patients with advanced CKD (88). There are various other factors responsible for chronic low-grade inflammation in CKD, which includes fluid retention and stress induced neuro-hormonal changes leading to an increased activity of the sympathetic nervous system. Subsequently, elevated glucocorticoids and inflammatory cytokines levels would lead to CKD (89). In addition, endotoxemia mediated microbial infection, endothelial activation, oxidative stress, dialysis related comprised immunity, obesity and certain genetic factors also potentially contribute to systemic inflammation-mediated CKD $(2,78)$. In this regard, it is known that levels of C-reactive protein, pentraxin-3, IL-10 and the ratio of IL-6 to IL-10 increase with the deterioration of kidney functions (90). In addition, chronic inflammation is a major factor responsible for the progression of sarcopenia in CKD. Moreover, acute inflammation in hyperlipidemic state could elevate Ang II levels, resulting in an increased oxidant stress and subsequent endothelial dysfunction, and thus contributing to further renal injury and fibrosis (91). The above-mentioned data substantially affirm the notion that inflammation in obesity contribute toward acceleration of the progression of kidney dysfunctions.

\section{Altered Renin-Angiotensin-Aldosterone System in Obesity}

RAAS is well-known for its role in regulating blood pressure and electrolyte balance (92). Recently, activation of RAAS in local tissues has been the subject of intense investigations $(93,94)$. Various investigators have suggested the importance of its activation in brain, adrenal gland, heart and kidney. Besides acquiring of angiotensin II (Ang II) in the kidney from circulation, the angiotensinogen (AGT), one of its upstream precursor, has been localized to proximal tubules. Whereas, angiotensin converting enzyme (ACE), that converts Ang I to Ang II, is present abundantly in proximal and distal tubules, and in collecting ducts (93). Renin produced by juxtaglomerular cells in kidney also paves a pathway for localized generation of Ang I. Thus, the kidney has all the necessary elements needed for the conversion of Ang I to Ang II. Ang II binds to type 1 Ang receptor (AT1) in the renal vasculature, leading to vasoconstriction and aldosterone production by the adrenal zona glomerulosa. Excessive release of this hormone is related to oxidative stress and cardiovascular disorders (95). Elevated aldosterone levels are observed in obese individuals, which has a positive correlation with high blood pressure, high waist circumference, and diminished HDL levels (96). Another detrimental factor in obese individuals include that adipose tissue produces inflammatory cytokines like TNF- $\alpha$ and interleukin- 6 (IL-6), and these are known to induce insulin resistance as well as to cause aldosterone secretion (93). In addition, conceivably, activation of RAAS system is associated toward accumulation of lipids in adipose tissues (93). In this regard, it is known that AGT is highly expressed in adipose tissues, and with its overexpression these mice were found to be obese $(97,98)$. Whereas, deletion of AGT protected the mice against HFDinduced obesity $(93,98)$. These data suggest that inhibitors or blockers of RAAS system can potentially attenuate obesity related hypertension therefore ameliorating renal dysfunctions. Along these lines hypertensive individuals were found to have excessive excretion of urinary angiotensinogen (UAGT), and administration of RAAS inhibitors suppressed UAGT secretion (99). In addition, administration of AT1 blockers lead to a significant reduction in urinary albumin excretion, suggesting a strong link between obesity, RAAS and renal dysfunctions (93).

\section{Altered Hemodynamic Changes in Kidney}

More than four decades ago, patients with obesity associated renal pathophysiological changes were reported (100). Since then, several studies have evaluated renal plasma flow (RPF) in obese and lean individuals. Some of these studies showed 9-33\% increase in $\operatorname{RPF}(12,101,102)$, while others showed no change or rather decrease in RPF $(12,101,102)$. In addition, filtration fraction was 9-29\% higher in obese participants $(101,103$, 104). Interestingly, two of the above studies showed that renal hemodynamic changes appear during the initial stages of obesity when $\mathrm{BMI}$ is $<30 \mathrm{Kg} / \mathrm{m}^{2}(12,102)$. The degree of increase in RPF was reported to be less than the GFR in obesity, indicating the presence of vasodilation primarily in the afferent arteriole along with vasoconstriction of efferent arteriole. Since it is difficult to calculate the transcapillary hydraulic pressure difference and ultrafiltration coefficient in humans, estimated values for GFR and RPF are the only parameters to roughly measure the changes in these variables (105). Nevertheless, it is known that systemic hypertension is accentuated in obese individuals (104). Conceivably, increased renal vasodilation and transcapillary hydraulic pressure in obese patients contributes to systemic hypertension. Elevated systemic hypertension to a certain extent can lead to hyperfiltration in these obese individuals as the dilated afferent arteriole subjects the glomerulus to an increased arterial pressure; thus accentuating the transcapillary hydraulic pressure difference and eventually elevating GFR in the initial stages of obesity (105). Clinical investigations assessing the changes in renal hemodynamics in patients with severe obesity before and 1 year after bariatric surgery showed a considerable decrease in BMI from $48 \mathrm{Kg} / \mathrm{m}^{2}$ to $32 \mathrm{Kg} / \mathrm{m}^{2}$ (103) and a considerable improvement in eGFR, RPF, albuminuric state and fractional clearance of albumin. These observations suggest that obesity 
related nephropathy is a reversible process following weight loss (103).

\section{TREATMENT OF OBESITY INDUCED NEPHROPATHY AND POSSIBLE THERAPEUTIC TARGETS}

\begin{abstract}
Reduction in proteinuria by various interventions yield a reno-protective effect in obesity-induced nephropathy/glomerulopathy. These may include administration of Renin-anigiotensin-aldosterone system (RAAS) inhibitors/antagonists, GLP-1 Receptor agonists, SGLT-2 inhibitors, and weight management either by dietary restriction or bariatric surgery. These are the best studied therapies, besides other possible measures that are still under investigation.
\end{abstract}

\section{RAAS Inhibition}

The activity of RAAS system can be reduced by several agents, including Angiotensin-Converting Enzyme (ACE) inhibitors, angiotensin type 1 receptor blockers, renin inhibitors, and aldosterone receptors antagonists. Obese patients that were administered ACE inhibitors showed $30-80 \%$ reduction in proteinuria $(12,106,107)$. In this regard, anti-proteinuric effect of Ramipril, an ACE inhibitor, was more effective in obese and overweight patient with high BMI than those with normal BMI (108). Clinical trials including large series of diabetic patients, showed significant effect of ACE inhibition on delaying the progression to ESRD. These findings suggested that patients subjected to RAAS inhibition for 1 year or longer could prevent CKD progression to ESRD (109). Reports also suggested decrease in the incidence of ESRD with the administration of Ramipril in relatively obese patients as compared to individuals who were mainly overweight. These findings confirm that obese patients are more responsive toward reno-protective effects of RAAS inhibition. Apparently, some of the studies indicated that effects of RAAS blockade tends to wane over a long period, partly because of weight gain in these individuals (108-110), hence these agents have limitated use. Other therapeutic measures may include the use of inhibitors of mineralocorticoids. The mineralocorticoid receptor (MR) activation has deleterious effects on renal structure and functions. In view of this biologic precept, recent efforts were made to establish MR antagonists as a new therapeutic tool. The therapeutic potential of the MR antagonists has been extensively explored in the amelioration of obesity and metabolic syndrome (111). Several preclinical studies suggested the usage of MR antagonist (MRA) have indeed dampened the progression of kidney disease (112). Likewise, a short-term study suggested that supplementation of spironolactone, an MRA, to ACE inhibition therapy significantly reduced albuminuria and blood pressure in obese patients (113). In addition, studies have shown that a third generation non-steroidal mineralocorticoid receptor antagonists like finerenone or eplerenone have potential to abrogate progression of kidney disease and its associated cardiovascular complications $(114,115)$.

\section{Weight Loss, Diet Management}

The effect of diet induced weight loss has been studied in obese patient having microvasculature complications in both nonrandomized prospective studies (12) and randomized control trials (RCT) (116). Some of these studies incorporated obese patients with T2DM, and in some trials, patients were subjected to low glycemic index diets accompanied with moderate exercise $(116,117)$. The BMI of all subjects ranged from 30 to $38 \mathrm{Kg} / \mathrm{m}^{2}$ before the trials, and it decreased significantly during the follow up. However, there were notable differences among patients as there were other factors that need to be considered before drawing any concrete conclusions, such as patient compliance and their personal habits pertaining to diet consumption and exercise. Nevertheless, there were remarkable changes related to weight loss and reduction in proteinuria in the above studies, thus establishing a firm causal relationship with one another. Proteinuria levels reduced significantly in patients who had more substantial weight loss. For instance, a RCT showed with weight loss of $4 \%$, there was a $30 \%$ decrease in proteinuria, and with further $6-10 \%$ reduction in weight the proteinuria decreased by $>70 \%(12,118)$. The meta-analysis of patients with CKD revealed reduction in BMI as well as in proteinuria (119). However, no significant changes in the glomerular filtration rate was observed among all these studies. Besides weight loss, the impact of low glycemic index diet or hypocaloric diets was not only confined to the amelioration of proteinuria, but there was a significant reduction in the elevated blood pressure, hyperlipidemia, fasting blood glucose and insulin resistance $(117,120)$. In addition, dietary management in obese men with weight loss and achieving waist circumference of $<102 \mathrm{~cm}$, also reduced the progression of retino-vascular complications and had improvement in the biomarkers of microvascular endothelial functions (121), suggesting an overall remarkable impact of diet management on obesity related vasulopathies and nephropathy.

\section{Weight Loss, Bariatric Surgery}

Mounting amount of evidence indicate a favorable impact of bariatric surgery in obese patients with T2DM (122). Several investigations have suggested a positive effect of bariatric surgery in obesity-associated nephropathy $(123,124)$. As alluded earlier, influence of bariatric surgery on weight loss or BMI were more dramatic compared to dietary management. An important observation with bariatric surgery in patients with high GFR relates to its significant restoration, and reduction in albuminuria or proteinuria. In addition, these changes were accompanied with considerable improvement in blood pressure, inflammatory and metabolic markers, and these beneficial changes persisted for 1-5 years after surgery (124). Several clinical case reports indicate a considerable amelioration of proteinuria and obesity-induced nephropathy following bariatric surgery $(125,126)$. However, bariatric surgery was accompanied with other unfavorable renal complications, such as nephrolithiasis, oxalate nephropathy and acute kidney injury (127). Studies have also shown a direct relationship between bariatric surgery and postoperative complications, such as surgical site infections, pneumonia, unplanned re-intubation, and prolonged postoperative ventilation, especially in patients with CKD (128). For instance, the risk of complications was 4.6\% 
in patients with normal renal functions with stage $1 \mathrm{CKD}$, and the incidence rose to $9.9 \%$ in patients with stage $5 \mathrm{CKD}$. In spite of the beneficial effects of bariatric surgery as indicated above, one cannot conclude that this surgical intervention can reverse CKD or ESRD progression completely (129).

\section{Glucagon Like Peptide-1 Receptor Agonist}

Until now RAAS inhibition has been considered the most effective treatment for obesity related kidney disorders (109). As mentioned before, their therapeutic benefits wane over a long period. Therefore, there is an urgency for finding new therapeutic targets for amelioration of obesity-induced diabetic nephropathy. Newer classes of anti-hyperglycemic drugs have shown encouraging results in obesity mediated renal dysfunctions (129). Recently, GLP-1 agonists showed promising results in dampening the development and progression of kidney disorders and improvement in declining eGFR and reduction in albuminuria (130). These drugs are known to exert beneficial effects in the kidney via enhancing glucose induced insulin secretion. The GLP-1 agonists include: Dulaglutide (Trulicity), Exenatide extended release (Bydureon), Exenatide (Byetta), Semaglutide (Ozempic), Semaglutide (Rybelsus), Liraglutide (Victoza), and Lixisenatide (Adlyxin), and within brackets are given the brand names of various manufacturing companies. The degree of weight reduction was different in various GLP1 receptor agonists. The GLP-1 agonists affect kidney functions in multiple ways besides increasing the insulin sensitivity. For instance, they can induce naturiesis and diuresis via inhibiting sodium-hydrogen exchanger (NHE3); conceivably this may indirectly affect the urinary excretion of albumin. Besides modulating albumin excretion, the GLP-1 agonists exert a multitude of other biological effects, for instance increasing the renal plasma flow and dampening the RAAS activation. They are also known to induce marginal improvement in renal hemodynamics. In addition, they have been shown to inhibit production and secretion of intestinal chylomicrons, and hence they have an important functional implication in lipid clearance. Although, GLP-1 agonists play an important role in attenuating the progression of obesity related renal disorders, they are less well-tolerated by patients with ESRD. Certainly, further research is needed to understand the mechanisms by which their effective use can be instituted (130).

Agreeably, anti-hyperglycemic effects of GLP-1 receptor agonist's are-known to reduce the risk of new or worsening kidney disease. Along these lines American Diabetic Association Standards of Care for the treatment of hyperglycemia in type 2 Diabetes state that GLP-1 receptor agonist should be incorporated in the therapeutic regimen if the said metabolic targets are not achieved by metformin in patients with cardiovascular diseases (131). United States Food and Drug Administration recently approve GLP-1 receptor agonist in combinations other drugs, for instance, insulin glargine/exanitide (Soliqua 100/33) and insulin degludec/liraglutide (Xultophy 100/3.6). There were two other trials, i.e., AWARD-7 and LEADER, which have been completed. The AWARD-7 trial pertained to the study of dulaglutide in patients with type 2 diabetes and moderate to severe CKD (131). The LEADER trial dealt with the study of
Liraglutide action in patients with diabetes with evaluation and cardiovascular outcome in CKD patients (132). The following table summarizes the list of both the clinical trials in patients with type 2 Diabetes $(130,132,133)$ :

\begin{tabular}{|c|c|c|c|c|}
\hline $\begin{array}{l}\text { Name of } \\
\text { the } \\
\text { study }\end{array}$ & $\begin{array}{l}\text { Drug or } \\
\text { intervention }\end{array}$ & $\begin{array}{l}\text { Study } \\
\text { population }\end{array}$ & $\begin{array}{l}\text { Renal } \\
\text { endpoints }\end{array}$ & Renal outcomes \\
\hline $\begin{array}{l}\text { AWARD- } \\
7\end{array}$ & $\begin{array}{l}\text { Dulaglutide } \\
0.75-1.5 \mathrm{mg} \\
\text { vs. insulin } \\
\text { glargine }\end{array}$ & $\begin{array}{l}N=57752 \% \\
\text { male, Mean } \\
\text { age: } 65, \\
\text { 52-week } \\
\text { treatment }\end{array}$ & $\begin{array}{l}\text { eGFR and UACR } \\
\text { change from } \\
\text { baseline }\end{array}$ & $\begin{array}{l}\text { Dulaglutide } \\
\text { glycemic control } \\
\text { was similar to } \\
\text { insulin glargine, } \\
\text { improved eGFR. } \\
\text { Moderate to } \\
\text { severe CKD } \\
\text { patients showed } \\
\text { improved glycemic } \\
\text { control with } \\
\text { Dulaglutide }\end{array}$ \\
\hline LEADER & $\begin{array}{l}\text { Liraglutide } \\
0.6-1.8 \mathrm{mg} \\
\text { vs. placebo }\end{array}$ & $\begin{array}{l}N=9,340 \\
64 \% \text { male, } \\
\text { Mean age: } \\
64, \text { Median } \\
\text { follow-up: } \\
3.84 \text { years }\end{array}$ & $\begin{array}{l}\text { Composite end } \\
\text { point New-onset } \\
\text { persistent, } \\
\text { albuminuria, } \\
\text { Persistent } \\
\text { doubling of sCr } \\
\text { and, eGFR }<45 \\
\mathrm{~mL} / \mathrm{min} / 1.73 \\
\mathrm{~m}^{2}, \text { Need for } \\
\text { continuous RRT, } \\
\text { Death due to } \\
\text { renal disease }\end{array}$ & $\begin{array}{l}\text { Lower composite } \\
\text { renal outcomes } \\
\text { were observed } \\
\text { with Liraglutide } \\
\text { than placebo, } \\
\text { primarily reducing } \\
\text { the new- onset of } \\
\text { persistent } \\
\text { albuminuria }\end{array}$ \\
\hline
\end{tabular}

$s C r$, serum creatinine; eGFR, estimated glomerular filtration rate in $\mathrm{mL} / \mathrm{min} / 1.73 \mathrm{~m}^{2}$; $U A C R$, urinary albumin-to-creatinine ratio; RRT, Renal replacement therapy.

\section{Sodium Glucose Co-transporter-2 (SGLT-2) Inhibitor}

Most of the patients with type 2 diabetes mellitus (T2DM) are obese, and that increases their risk of development of cardio-renal complications; thus, sustained reduction in body weight is imperative for a healthy lifestyle (131). Majority of glucose lowering drugs like insulin, sulfonylureas, glinides, thiazolidinediones increase body weight; making weight management difficult in already obese T2DM patients. SGLT-2 blockers are the only glucose lowering drugs, which decrease the body weight. These drugs selectively and reversibly inhibit SGLT-2 transporters in proximal tubules, preventing glucose absorption and increasing its urinary excretion with consequential loss of calories (131). In addition, these blockers decrease insulin:glucagon ratio, thus increasing the degree of lipolysis, leading to weight loss and reduction in fat mass. Recently, a single center Real-World study from India showed mean weight loss of $3.2-3.9 \mathrm{~kg}$ with SGLT-2 inhibitors used for 6-12 month (134). In Western population SGLT-2 inhibitor (dapagliflozin) in combination with metformin administered for 24 weeks reduced the waist circumference by -1.7 to $-2.7 \mathrm{~cm}$ compared to $-1.3 \mathrm{~cm}$ in placebo (metformin) group (134). Treatment with ipragliflozin for 24 weeks led to a reduction in visceral fat volume and intrahepatic lipid accumulation in Japanese population (131). However, SGLT-2 inhibitors alone are 
not highly effective in overall body weight reduction, as other counter mechanisms become operative to maintain body weight. Incidentally, SGLT-2 inhibitors in combination with GLP-1 receptor agonists effectively accentuate in the reduction of body weight $(131,135)$. For instance, dapagliflozin (SGLT2 inhibitor) alone inadequately controlled blood sugar levels in patients with type 2 diabetes undergoing metformin monotherapy (DURATION-8). But when dapagliflozin (SGLT2 inhibitor) was combined with exenatide (GLP1-RA) in patients with T2DM, both effectively reduced the mean body weight (136). Several other investigators have shown that SGLT-2 inhibitors reduce the risk of progression of renal disease in T2D subjects via possible mechanisms like reducing glomerular capillary pressure and albuminuria, and therefore attenuating renal impairment $(135,137)$.

\section{SREBP Inhibitors}

Accumulating evidence have shown that overexpression of SREBP-1 in hyperlipidemic settings is the major driver of tubulointerstitial injury via up-regulating pro-inflammatory cytokines and pro-fibrogenic growth factors $(65,138)$. These findings led to a search for inhibitors of these cytokines and transcription factors. The farnesoid X-activated receptor (FXR) agonists attenuate SREBP-1 expression, lipid deposition, inflammation and fibrosis in the settings of obesity $(130,139)$. In addition, vitamin D receptor (VDR) agonists also inhibit SREBP-1, lipid accumulation and thereby reducing fibrosis (67). As mentioned above, SREBP-2 is a regulator of cholesterol synthesis, and exploration of small molecules that can inhibit its transcriptional activity, is the subject matter of ongoing research. Studies have shown that diet management in aged mice and administration of VDR agonists decreased SREBP-2 expression and activity in the kidney $(12,63,67)$. This prevented cholesterol deposition and improved declining renal functions (67). In addition, other investigators have demonstrated anti-Inflammatory effects of ANG-(1-7) in ameliorating HFD-induced renal injury via LDLrSREBP2-SCAP Pathway (140).

\section{Alternative Approaches}

Another strategy, which can limit the accumulation of fatty acids and triacylglycerides, is to increase fatty acid oxidation via activation of PPAR $\alpha$. The notion of usage of PPAR $\alpha$ agonist is derived from the fact that there is a considerable decrease in PPAR $\alpha$ expression and fatty acid oxidation enzymes in kidney biopsy samples of patient suffering from obesity associated nephropathy and diabetes (45). PPAR $\alpha$ agonist fenofibrate ameliorated the progression of kidney disease in HFD fed mice (141) and in diabetic $d b / d b$ mice (142). In addition, large-scale studies have shown that elafibranor, a PPAR $\alpha$ agonist, reduces the progression of albuminuria, however, there is also transient reduction in GFR. These data suggest that long-term use of these agents may reduce loss of renal functions (143). Another alternative approach to limit the deposition of cholesterol, which can be achieved by accentuating its efflux. Liver X receptor (LXR) has a major role in cholesterol efflux, which conceivably could decrease inflammation and atherosclerosis $(144,145)$. LXR is known to induce cholesterol efflux in renal cells (146). Renal biopsy samples from diabetic patients with obesity related nephropathy had decreased expression of LXR and of enzymes involved in cholesterol efflux (147). However, the mechanisms behind the accentuated cholesterol deposition, and decreased LXR expression are not fully understood. Inflammation downregulates LXR expression in renal cells (148). LXR agonist in diabetic mice reduces cholesterol accumulation, inflammation, and finally prevents the progression of renal disease (149). Paradoxically, LXR knockout mice were not protective against diabetic nephropathy (150) as these mice (LXR $\alpha / \beta^{-/-}$) had increased cholesterol accumulation, inflammation and oxidative stress (150). These reports suggest crucial homeostatic role for LXR in maintaining proper kidney functionality. LXR upregulation also reduces renin-angiotensin-aldosterone activation (151) and limits ENaC-mediated sodium transport (152), and cystic fibrosis transmembrane conductance regulator (CFTR)mediated chloride transporter in collecting ducts (153). In line with these biologic precepts, administration of LXR agonist with cyclodextrin has been shown to significantly improve renal function in BTBR ob/ob mice (154).

\section{CONCLUSION AND SUMMARY}

Increased BMI not only directly affects renal cells, but also indirectly accentuates kidney damage via accelerating hypertension, atherosclerosis and progression of T2DM. Obesity onset increases GFR, RPF and tubular reabsorption of sodium, and also promotes glomerular hypertension. Long standing hyperglycemia accompanied with untreated obesity leads to proteinuria and albuminuria. These changes eventually damage the kidney, and lead to one third of patients developing ESRD. Genetic elements like: gestational diabetes, low nephron number, reduced renal mass, as well as socioeconomic issues have been described as the predisposing factors for obesity associated renal changes, i.e., CKD. Ectopic lipid accumulation in podocytes as a result of uncontrolled obesity also leads to pathologic alterations in renal cells. This leads to progressive albuminuria, oxidative stress and interstitial fibrosis. In addition, lipid accumulation in renal cells leads to insulin resistance. HDL has been regarded as an essential indicator of good health due to its retrograde cholesterol transport, anti-inflammatory and -oxidant properties. Abnormalities in HDL homeostasis leading to hyperlipidemia eventually culminates into the progression of kidney disease, as HDL levels are substantially reduced in majority of kidney disorders. Thus, it seems that interventions improving the HDL status would be one of the good strategies to dampen the progression of $\mathrm{CKD}$. In the regard, one of the other potential therapy would be the blockade of RAAS, although its reno-protective effects are not long lasting. Weight reduction by dietary management or by bariatric surgery has yielded consistent results in limiting the progression of kidney disease. Obesity mediated renal disorder is characterized by altered fatty acid and cholesterol metabolism, and they have important role in modulating inflammation, oxidative stress and fibrosis. Along these lines, the SREBP antagonist, agonist of PPAR $\alpha$, GLP-1RA, SGLT-2 blockers and ongoing clinical trials focusing on dietary intervention hold promise for the treatment of obesity mediated nephropathy. However, we still need more data related to 
The table enlists ongoing trials (data collected from ClinicalTrials.gov).

\begin{tabular}{|c|c|c|c|c|}
\hline Intervention/treatment & Species & Condition & $\begin{array}{l}\text { Primary kidney } \\
\text { outcome }\end{array}$ & Secondary kidney outcome \\
\hline $\begin{array}{l}\text { Conventional low salt education, } \\
\text { Intensive low salt dietary education by } \\
\text { smartphone application }\end{array}$ & Human & Albuminuria & $\begin{array}{l}\text { Decrements of 24-h urine } \\
\text { albumin levels } 12 \text { weeks } \\
\text { after low salt diet } \\
\text { education }\end{array}$ & $\begin{array}{l}\text { Decrements of 24-h urine sodium, } \\
\text { Change of blood pressure }\end{array}$ \\
\hline $\begin{array}{l}3.6 \mathrm{~g} \text { of Sodium butyrate, } 6 \text { capsules } \\
\text { twice daily for } 12 \text { weeks. }\end{array}$ & Human & $\begin{array}{l}\text { Diabetes Mellitus, } \\
\text { Albuminuria }\end{array}$ & $\begin{array}{l}\text { Change in Intestinal } \\
\text { inflammation }\end{array}$ & $\begin{array}{l}\text { Change in urinary } \\
\text { albumin-creatinine ratio (UACR), } \\
\text { Change in eGFR }\end{array}$ \\
\hline Low Sodium Diet & Human & $\begin{array}{l}\text { Chronic kidney disease } \\
\text { albuminuria }\end{array}$ & $\begin{array}{l}\text { Net change in urinary } \\
\text { albumin-to-creatinine ratio }\end{array}$ & $\begin{array}{l}\text { Net change in urinary albumin, } \\
\text { eGFR, blood pressure }\end{array}$ \\
\hline $\begin{array}{l}\text { SGLT2 Inhibition: Dapagliflozine } \\
5-10 \text { mg or Empagliflozin } 10 \text { mg or } \\
\text { Canagliflozin } 100 \text { mg once daily tablet } \\
\text { treatment }\end{array}$ & Human & Diabetic Nephropathy & $\begin{array}{l}\text { Change in urinary } \\
\text { albuminuria, eGFR, } \\
\text { Nephrin, TGF- } \beta 1, I L-6 \text {, } \\
\text { TNF- } \alpha\end{array}$ & $\begin{array}{l}\text { Change in uric acid, aldosterone, } \\
\text { renin, angiotensin }\end{array}$ \\
\hline $\begin{array}{l}\text { Mineralocorticoid receptor } \\
\text { Drug: spironolactone } 25 \mathrm{mg} \text { daily for } \\
\text { the } 1 \text { st or } 2 \text { nd } 6 \text { week treatment } \\
\text { period. } \\
\text { Drug: Amiloride } 5 \mathrm{mg} \text { daily for the } 1 \mathrm{st} \\
\text { or } 2 \text { nd } 6 \text { week treatment period. }\end{array}$ & Human & $\begin{array}{l}\text { Chronic kidney disease } \\
\text { albuminuria }\end{array}$ & $\begin{array}{l}\text { Change in oxidative stress } \\
\text { as measured by urine } \\
\text { levels of F2-isoprostanes, } \\
\text { albuminuria }\end{array}$ & $\begin{array}{l}\text { Change in serum potassium, } \\
\text { glomerular filtration rate }\end{array}$ \\
\hline $\begin{array}{l}\text { Drug: Sodium zirconium cyclosilicate } \\
\text { LOKELMA }^{\circledR} 5 \mathrm{gm} \text { Powder for Oral } \\
\text { Suspension }\end{array}$ & Human & $\begin{array}{l}\text { Type } 2 \text { Diabetes } \\
\text { Mellitus with kidney } \\
\text { complications }\end{array}$ & $\begin{array}{l}\text { Urinary albumin creatinine } \\
\text { ratio }\end{array}$ & $\begin{array}{l}\text { Estimation of glomerular filtration } \\
\text { rate (eGFR), urinary sodium, } \\
\text { potassium }\end{array}$ \\
\hline $\begin{array}{l}\text { Drug: Sulfa-zero possible benefits of } \\
\text { the treatment of new generation } \\
\text { hypoglycaemic drugs compared to } \\
\text { sulphonylureas }\end{array}$ & Human & $\begin{array}{l}\text { Type } 2 \text { diabetes } \\
\text { mellitus diet, healthy } \\
\text { renal function disorder, } \\
\text { albuminuria }\end{array}$ & $\begin{array}{l}\text { Evaluation of } \\
\text { glycometabolic } \\
\text { parameters, therapeutic } \\
\text { adherence, Long term } \\
\text { diabetic complications }\end{array}$ & Evaluation of insulin sensitivity, \\
\hline $\begin{array}{l}\text { Fasting mimicking diet: Prolon } \\
\text { Dietary Supplement: Food } \\
\text { supplement Endocalyx-4 capsules a } \\
\text { day of the food supplement for } 3 \\
\text { months. }\end{array}$ & Human & $\begin{array}{l}\text { Diabetic nephropathy, } \\
\text { albuminuria, Type } 2 \\
\text { diabetes mellitus, } \\
\text { glucose metabolism } \\
\text { disorders, } \\
\text { microalbuminuria }\end{array}$ & $\begin{array}{l}\text { Percentage change from } \\
\text { baseline in the } \\
\text { microvascular health index } \\
\text { to the placebo group }\end{array}$ & $\begin{array}{l}\text { Percentage change in Urine } \\
\text { albumin-to-creatinine ratio, urinary } \\
\text { heparanase levels, urinary MCP-1 } \\
\text { levels, specific urinary heparan } \\
\text { sulfate }\end{array}$ \\
\hline $\begin{array}{l}\text { Drug: Micro-particle Curcumin } \\
\text { Three } 30 \text { mg capsules once daily, } \\
\text { self-administered for } 6 \text { months }\end{array}$ & Human & Chronic Kidney Disease & $\begin{array}{l}\text { Percent difference } \\
\text { between baseline and } 24 \\
\text { week ( } 6 \text { month) } \\
\text { albuminuria, Change in } \\
\text { eGFR }\end{array}$ & $\begin{array}{l}\text { Renal failure composite, Glycemic } \\
\text { control as assessed by change in } \\
\text { the percentage of glycated } \\
\text { hemoglobin }\end{array}$ \\
\hline $\begin{array}{l}\text { Behavioral: Coaching DASH group } \\
\text { (C-DASH) } \\
\text { Behavioral: Self-Shopping DASH } \\
\text { group (S-DASH) }\end{array}$ & Human & $\begin{array}{l}\text { Chronic kidney } \\
\text { disease, hypertension }\end{array}$ & Change in Albuminuria & Change in systolic blood pressure \\
\hline
\end{tabular}

bariatric surgeries to conclude more affirmatively regarding its beneficial effects in CKD. Besides these drug or surgical remedies, we need to explore new therapeutic avenues which could target the abnormalities in fat metabolism to combat obesity related CKD.

\section{REFERENCES}

1. Coresh J, Selvin E, Stevens LA, Manzi J, Kusek JW, Eggers P, et al. Prevalence of chronic kidney disease in the United States. JAMA. (2007) 298:203847. doi: 10.1001/jama.298.17.2038

2. Stenvinkel P, Zoccali C Ikizler TA. Obesity in CKD-what should nephrologists know? J Am Soc Nephrol. (2013) 24:172736. doi: 10.1681/ASN.2013040330

\section{AUTHOR CONTRIBUTIONS}

IS: writing-original draft, review, and editing. YL, XZ, and YK: review editing. All authors have read and agreed to the submitted version of the manuscript.

3. Guebre-Egziabher F, Alix PM, Koppe L, Pelletier CC, Kalbacher E, Fouque D, et al. Ectopic lipid accumulation: A potential cause for metabolic disturbances and a contributor to the alteration of kidney function. Biochimie. (2013) 95:1971-9. doi: 10.1016/j.biochi.2013. 07.017

4. Nolan E, O'Meara YM Godson C. Lipid mediators of inflammation in obesity-related glomerulopathy. Nephrol Dial Transplant. (2013) 28(Suppl. 4):iv22-9. doi: 10.1093/ndt/gft392 
5. Wickman C Kramer H. Obesity and kidney disease: potential mechanisms. Semin Nephrol. (2013) 33:14-22. doi: 10.1016/j.semnephrol.2012.12.006

6. de Vries AP, Ruggenenti P, Ruan XZ, Praga M, Cruzado JM, Bajema IM, et al. Fatty kidney: emerging role of ectopic lipid in obesity-related renal disease. Lancet Diabetes Endocrinol. (2014) 2:417-26. doi: 10.1016/S2213-8587(14)70065-8

7. Zammit AR, Katz MJ, Derby C, Bitzer M Lipton RB. Chronic kidney disease in non-diabetic older adults: associated roles of the metabolic syndrome, inflammation, and insulin resistance. PLOS ONE. (2015) 10:e0139369. doi: 10.1371/journal.pone.0139369

8. Wang L, Southerland J, Wang K, Bailey BA, Alamian A, Stevens MA, et al. Ethnic differences in risk factors for obesity among adults in California, the United States. J Obes. (2017) 2017:2427483. doi: 10.1155/2017/2427483

9. Wang Y, Beydoun MA, Liang L, Caballero B Kumanyika SK. Will all Americans become overweight or obese? Estimating the progression and cost of the US obesity epidemic. Obesity. (2008) 16:2323-30. doi: 10.1038/oby.2008.351

10. Obermayr RP, Temml C, Knechtelsdorfer M, Gutjahr G, Kletzmayr J, Heiss $\mathrm{S}$, et al. Predictors of new-onset decline in kidney function in a general middle-European population. Nephrol Dial Transplant. (2008) 23:126573. doi: $10.1093 / \mathrm{ndt} / \mathrm{gfm} 790$

11. Consultation WHOE. Appropriate body-mass index for Asian populations and its implications for policy and intervention strategies. Lancet. (2004) 363:157-63. doi: 10.1016/S0140-6736(03)15268-3

12. D'Agati VD, Chagnac A, de Vries AP, Levi M, Porrini E, HermanEdelstein $M$, et al. Obesity-related glomerulopathy: clinical and pathologic characteristics and pathogenesis. Nat Rev Nephrol. (2016) 12:453-71. doi: 10.1038/nrneph.2016.75

13. Agarwal R, Bills JE, Light RP. Diagnosing obesity by body mass index in chronic kidney disease: an explanation for the "obesity paradox?" Hypertension. (2010) 56:893900. doi: 10.1161/HYPERTENSIONAHA.110.160747

14. Zaman SB, Hossain N, Rahman M. Associations between Body Mass Index and Chronic Kidney Disease in Type 2 Diabetes Mellitus Patients: Findings from the Northeast of Thailand. Diabetes Metab J. (2018) 42:330337. doi: $10.4093 / \mathrm{dmj} .2017 .0052$

15. Kovesdy CP, Furth S, Zoccali C World Kidney Day Steering C. Obesity and kidney disease: Hidden consequences of the epidemic. Indian J Nephrol. (2017) 27:85-92. doi: 10.1177/2054358117698669

16. Zoccali C, Torino C, Tripepi G, Mallamaci F. Assessment of obesity in chronic kidney disease: what is the best measure? Curr Opin Nephrol Hypertens. (2012) 21:641-6. doi: 10.1097/MNH.0b013e328358a02b

17. Afkarian M, Sachs MC, Kestenbaum B, Hirsch IB, Tuttle KR, Himmelfarb J, et al. Kidney disease and increased mortality risk in type 2 diabetes. J Am Soc Nephrol. (2013) 24:302-8. doi: 10.1681/ASN.2012070718

18. Ma RCW. Epidemiology of diabetes and diabetic complications in China. Diabetologia. (2018) 61:1249-60. doi: 10.1007/s00125-018-4557-7

19. Varughese S Abraham G. Chronic kidney disease in India: A clarion call for change. Clin J Am Soc Nephrol. (2018) 13:802-4. doi: 10.2215/CJN.09180817

20. Goncalves GMR Silva END. Cost of chronic kidney disease attributable to diabetes from the perspective of the Brazilian Unified Health System. PLoS ONE. (2018) 13:e0203992. doi: 10.1371/journal.pone.0203992

21. Sharma SG, Bomback AS, Radhakrishnan J, Herlitz LC, Stokes MB, Markowitz GS, et al. The modern spectrum of renal biopsy findings in patients with diabetes. Clin J Am Soc Nephrol. (2013) 8:171824. doi: $10.2215 / \mathrm{CJN} .02510213$

22. Drong AW, Lindgren CM McCarthy MI. The genetic and epigenetic basis of type 2 diabetes and obesity. Clin Pharmacol Ther. (2012) 92:70715. doi: $10.1038 /$ clpt.2012.149

23. Yang J, Loos RJ, Powell JE, Medland SE, Speliotes EK, Chasman DI, et al. FTO genotype is associated with phenotypic variability of body mass index. Nature. (2012) 490:267-72. doi: 10.1038/nature11401

24. Taubes G. Treat obesity as physiology, not physics. Nature. (2012) 492:155. doi: 10.1038/492155a

25. Perez-Pozo SE, Schold J, Nakagawa T, Sanchez-Lozada LG, Johnson RJ Lillo JL. Excessive fructose intake induces the features of metabolic syndrome in healthy adult men: role of uric acid in the hypertensive response. Int $J$ Obes. (2010) 34:454-61. doi: 10.1038/ijo.2009.259
26. Johnson RJ, Segal MS, Sautin Y, Nakagawa T, Feig DI, Kang DH, et al. Potential role of sugar (fructose) in the epidemic of hypertension, obesity and the metabolic syndrome, diabetes, kidney disease, and cardiovascular disease. Am J Clin Nutr. (2007) 86:899-906. doi: 10.1093/ajcn/86.4.899I

27. Johnson RJ, Sanchez-Lozada LG Nakagawa T. The effect of fructose on renal biology and disease. J Am Soc Nephrol. (2010) 21:20369. doi: 10.1681/ASN.2010050506

28. Aston LM. Glycaemic index and metabolic disease risk. Proc Nutr Soc. (2006) 65:125-34. doi: 10.1079/PNS2005485

29. Knight JA. Physical inactivity: associated diseases and disorders. Ann Clin Lab Sci. (2012) 42:320-37.

30. Cook RL, O'Dwyer NJ, Donges CE, Parker HM, Cheng HL, Steinbeck KS, et al. Relationship between obesity and cognitive function in young women: the food, mood and mind study. J Obes. (2017) 2017:5923862. doi: 10.1155/2017/5923862

31. van der Valk ES, Savas $M$ van Rossum EFC. Stress and obesity: are there more susceptible individuals? Curr Obes Rep. (2018) 7:193203. doi: 10.1007/s13679-018-0306-y

32. Thaker VV. Genetic and epigenetic causes of obesity. Adolesc Med State Art Rev. (2017) 28:379-405.

33. Sivamaruthi BS, Kesika P, Suganthy N Chaiyasut C. A review on role of microbiome in obesity and antiobesity properties of probiotic supplements. Biomed Res Int. (2019) 2019:3291367. doi: 10.1155/2019/3291367

34. Tambo A, Roshan MH Pace NP. The microbial hypothesis: contributions of adenovirus infection and metabolic endotoxaemia to the pathogenesis of obesity. Int J Chronic Dis. (2016) 2016:7030795. doi: 10.1155/2016/7030795

35. Luyckx VA Brenner BM. Birth weight, malnutrition and kidneyassociated outcomes-a global concern. Nat Rev Nephrol. (2015) 11:135-49. doi: 10.1038/nrneph.2014.251

36. Abitbol CL, Chandar J, Rodriguez MM, Berho M, Seeherunvong W, Freundlich $\mathrm{M}$, et al. Obesity and preterm birth: additive risks in the progression of kidney disease in children. Pediatr Nephrol. (2009) 24:136370. doi: 10.1007/s00467-009-1120-2

37. Shulman GI. Ectopic fat in insulin resistance, dyslipidemia, and cardiometabolic disease. N Engl J Med. (2014) 371:113141. doi: 10.1056/NEJMra1011035

38. van Zonneveld AJ Rabelink TJ. Mesangial cells defy LDL receptor paradigm. Kidney Int. (2001) 60:2037-8. doi: 10.1046/j.1523-1755.2001.00023.x

39. Li Z, Woollard JR, Wang S, Korsmo MJ, Ebrahimi B, Grande JP, et al. Increased glomerular filtration rate in early metabolic syndrome is associated with renal adiposity and microvascular proliferation. Am J Physiol Renal Physiol. (2011) 301:F1078-87. doi: 10.1152/ajprenal.00333.2011

40. Chung JJ, Huber TB, Godel M, Jarad G, Hartleben B, Kwoh C, et al. Albuminassociated free fatty acids induce macropinocytosis in podocytes. J Clin Invest. (2015) 125:2307-16. doi: 10.1172/JCI79641

41. Clement LC, Avila-Casado C, Mace C, Soria E, Bakker WW, Kersten $\mathrm{S}$, et al. Podocyte-secreted angiopoietin-like- 4 mediates proteinuria in glucocorticoid-sensitive nephrotic syndrome. Nat Med. (2011) 17:11722. doi: $10.1038 / \mathrm{nm} .2261$

42. Wirthensohn G, Guder WG. Renal lipid metabolism. Miner Electrolyte Metab. (1983) 9:203-11.

43. Ruan XZ, Varghese Z Moorhead JF. An update on the lipid nephrotoxicity hypothesis. Nat Rev Nephrol. (2009) 5:713-21. doi: 10.1038/nrneph.2009.184

44. Nishi H, Higashihara T Inagi R. Lipotoxicity in kidney, heart, and skeletal muscle dysfunction. Nutrients. (2019) 11:71664. doi: 10.3390/nu11071664

45. Kang HM, Ahn SH, Choi P, Ko YA, Han SH, Chinga F, et al. Defective fatty acid oxidation in renal tubular epithelial cells has a key role in kidney fibrosis development. Nat Med. (2015) 21:37-46. doi: 10.1038/nm.3762

46. Sun YB, Qu X, Howard V, Dai L, Jiang X, Ren Y, et al. Smad3 deficiency protects mice from obesity-induced podocyte injury that precedes insulin resistance. Kidney Int. (2015) 88:286-98. doi: 10.1038/ki.2015.121

47. Tiwari S, Singh RS, Li L, Tsukerman S, Godbole M, Pandey G, et al. Deletion of the insulin receptor in the proximal tubule promotes hyperglycemia. J Am Soc Nephrol. (2013) 24:1209-14. doi: 10.1681/ASN.2012060628

48. Mather A, Pollock C. Glucose handling by the kidney. Kidney Int Suppl. (2011) 120:S1-6. doi: 10.1038/ki.2010.509

49. Gerich JE. Role of the kidney in normal glucose homeostasis and in the hyperglycaemia of diabetes mellitus: therapeutic implications. 
Diabet Med. (2010) 27:136-42. doi: $10.1111 /$ j.1464-5491.2009.0 2894.x

50. Gronda E, Jessup M, Iacoviello M, Palazzuoli A, Napoli C. Glucose metabolism in the kidney: neurohormonal activation and heart failure development. J Am Heart Assoc. (2020) 9:e018889. doi: 10.1161/JAHA.120.018889

51. Meyer C, Dostou J, Nadkarni V Gerich J. Effects of physiological hyperinsulinemia on systemic, renal, and hepatic substrate metabolism. Am J Physiol. (1998) 275:F915-21. doi: 10.1152/ajprenal.1998.275.6.F915

52. Bandet CL, Tan-Chen S, Bourron O, Le Stunff H, Hajduch E. Sphingolipid metabolism: new insight into ceramide-induced lipotoxicity in muscle cells. Int J Mol Sci. (2019) 20:479. doi: 10.3390/ijms20030479

53. Petersen MC Shulman GI. Roles of diacylglycerols and ceramides in hepatic insulin resistance. Trends Pharmacol Sci. (2017) 38:64965. doi: 10.1016/j.tips.2017.04.004

54. Iwai T, Kume S, Chin-Kanasaki M, Kuwagata S, Araki H, Takeda $\mathrm{N}$, et al. Stearoyl-CoA desaturase-1 protects cells against lipotoxicitymediated apoptosis in proximal tubular cells. Int J Mol Sci. (2016) 17:1868. doi: 10.3390/ijms17111868

55. Sieber J, Weins A, Kampe K, Gruber S, Lindenmeyer MT, Cohen $\mathrm{CD}$, et al. Susceptibility of podocytes to palmitic acid is regulated by stearoyl-CoA desaturases 1 and 2. Am J Pathol. (2013) 183:73544. doi: 10.1016/j.ajpath.2013.05.023

56. Chin HJ, Fu YY, Ahn JM, Na KY, Kim YS, Kim S, et al. Omacor, n-3 polyunsaturated fatty acid, attenuated albuminuria and renal dysfunction with decrease of SREBP-1 expression and triglyceride amount in the kidney of type II diabetic animals. Nephrol Dial Transplant. (2010) 25:14507. doi: $10.1093 /$ ndt/gfp695

57. Mount P, Davies M, Choy SW, Cook N Power D. Obesity-related chronic kidney disease-the role of lipid metabolism. Metabolites. (2015) 5:72032. doi: 10.3390/metabo5040720

58. Yang X, Okamura DM, Lu X, Chen Y, Moorhead J, Varghese Z, et al. CD36 in chronic kidney disease: novel insights and therapeutic opportunities. Nat Rev Nephrol. (2017) 13:769-81. 126I. doi: 10.1038/nrneph.2017.126

59. Opazo-Rios L, Mas S, Marin-Royo G, Mezzano S, Gomez-Guerrero C, Moreno JA, et al. Lipotoxicity and diabetic nephropathy: novel mechanistic insights and therapeutic opportunities. Int J Mol Sci. (2020) 21:2632. doi: 10.3390/ijms21072632

60. Horton JD, Shah NA, Warrington JA, Anderson NN, Park SW, Brown MS, et al. Combined analysis of oligonucleotide microarray data from transgenic and knockout mice identifies direct SREBP target genes. Proc Natl Acad Sci USA. (2003) 100:12027-32. doi: 10.1073/pnas.15349 23100

61. Tominaga T, Dutta RK, Joladarashi D, Doi T, Reddy JK Kanwar YS. Transcriptional and translational modulation of myo-Inositol Oxygenase (Miox) by fatty acids: implications in renal tubular injury induced in obesity and diabetes. J Biol Chem. (2016) 291:1348-67. doi: 10.1074/jbc.M115.698191

62. Sun L, Halaihel N, Zhang W, Rogers T Levi M. Role of sterol regulatory element-binding protein 1 in regulation of renal lipid metabolism and glomerulosclerosis in diabetes mellitus. J Biol Chem. (2002) 277:1891927. doi: 10.1074/jbc.M110650200

63. Im SS, Yousef L, Blaschitz C, Liu JZ, Edwards RA, Young SG, et al. Linking lipid metabolism to the innate immune response in macrophages through sterol regulatory element binding protein-1a. Cell Metab. (2011) 3:540-9. doi: 10.1016/j.cmet.2011.04.001

64. Wang TN, Chen X, Li R, Gao B, Mohammed-Ali Z, Lu C, et al. SREBP1 mediates angiotensin II-induced TGF-betal upregulation and glomerular fibrosis. J Am Soc Nephrol. (2015) 26:1839-54. doi: 10.1681/ASN.2013121332

65. Jiang T, Wang Z, Proctor G, Moskowitz S, Liebman SE, Rogers T, et al. Diet-induced obesity in $\mathrm{C} 57 \mathrm{BL} / 6 \mathrm{~J}$ mice causes increased renal lipid accumulation and glomerulosclerosis via a sterol regulatory elementbinding protein-1c-dependent pathway. J Biol Chem. (2005) 280:3231725. doi: 10.1074/jbc.M500801200

66. Proctor G, Jiang T, Iwahashi M, Wang Z, Li J Levi M. Regulation of renal fatty acid and cholesterol metabolism, inflammation, and fibrosis in Akita and OVE26 mice with type 1 diabetes. Diabetes. (2006) 55:25029. doi: $10.2337 / \mathrm{db} 05-0603$
67. Wang XX, Jiang T, Shen Y, Santamaria H, Solis N, Arbeeny C, et al. Vitamin D receptor agonist doxercalciferol modulates dietary fat-induced renal disease and renal lipid metabolism. Am J Physiol Renal Physiol. (2011) 300:F801-10. doi: 10.1152/ajprenal.00338.2010

68. Ruan XZ, Varghese Z, Powis SH Moorhead JF. Dysregulation of LDL receptor under the influence of inflammatory cytokines: a new pathway for foam cell formation. Kidney Int. (2001) 60:1716-25. doi: 10.1046/j.1523-1755.2001.00025.x

69. Yuan Y, Zhao L, Chen Y, Moorhead JF, Varghese Z, Powis SH, et al. Advanced glycation end products (AGEs) increase human mesangial foam cell formation by increasing Golgi SCAP glycosylation in vitro. Am J Physiol Renal Physiol. (2011) 301:F236-43. doi: 10.1152/ajprenal.00646.2010

70. Zheng Y, Tang L, Huang W, Yan R, Ren F, Luo L, et al. Antiinflammatory effects of Ang-(1-7) in ameliorating HFD-induced renal injury through LDLr-SREBP2-SCAP pathway. PLoS ONE. (2015) 10:e136187. doi: 10.1371/journal.pone.0136187

71. Kim HJ, Moradi H, Yuan J, Norris K Vaziri ND. Renal mass reduction results in accumulation of lipids and dysregulation of lipid regulatory proteins in the remnant kidney. Am J Physiol Renal Physiol. (2009) 296:F1297306. doi: 10.1152/ajprenal.90761.2008

72. Nakagawa H. How endoplasmic reticulum stress contributes to obesity-driven hepatic tumorigenesis. Hepat Oncol. (2015) 2:209-11. doi: 10.2217/hep.15.11

73. Vaziri ND. HDL abnormalities in nephrotic syndrome and chronic kidney disease. Nat Rev Nephrol. (2016) 12:37-47. doi: 10.1038/nrneph.2015.180

74. Moradi H, Pahl MV, Elahimehr R Vaziri ND. Impaired antioxidant activity of high-density lipoprotein in chronic kidney disease. Transl Res. (2009) 153:77-85. doi: 10.1016/j.trsl.2008.11.007

75. Brites F, Martin M, Guillas I Kontush A. Antioxidative activity of highdensity lipoprotein (HDL): Mechanistic insights into potential clinical benefit. BBA Clin. (2017) 8:66-77. doi: 10.1016/j.bbacli.2017.07.002

76. Reiss AB, Voloshyna I, De Leon J, Miyawaki N, Mattana J. Cholesterol metabolism in CKD. Am J Kidney Dis. (2015) 66:1071-82. doi: 10.1053/j.ajkd.2015.06.028

77. Dirican M, Akca R, Sarandol E, Dilek K. Serum paraoxonase activity in uremic predialysis and hemodialysis patients. J Nephrol. (2004) 17:813-8.

78. Yamamoto S, Yancey PG, Ikizler TA, Jerome WG, Kaseda R, Cox B, et al. Dysfunctional high-density lipoprotein in patients on chronic hemodialysis. J Am Coll Cardiol. (2012) 60:2372-9. doi: 10.1016/j.jacc.2012.09.013

79. Gluba-Brzozka A, Franczyk B Rysz J. Cholesterol disturbances and the role of proper nutrition in CKD patients. Nutrients. (2019) 11:2020. doi: 10.3390/nu11112820

80. Vaziri ND, Navab K, Gollapudi P, Moradi H, Pahl MV, Barton $\mathrm{CH}$, et al. Salutary effects of hemodialysis on low-density lipoprotein proinflammatory and high-density lipoprotein anti-inflammatory properties in patient with end-stage renal disease. J Natl Med Assoc. (2011) 103:52433. doi: 10.1016/S0027-9684(15)30368-0

81. Dantoine TF, Debord J, Charmes JP, Merle L, Marquet P, Lachatre G, et al. Decrease of serum paraoxonase activity in chronic renal failure. J Am Soc Nephrol. (1998) 9:2082-8. doi: 10.1681/ASN.V9112082

82. Birjmohun RS, van Leuven SI, Levels JH, van 't Veer C, Kuivenhoven JA, Meijers JC, et al. High-density lipoprotein attenuates inflammation and coagulation response on endotoxin challenge in humans. Arterioscler Thromb Vasc Biol. (2007) 27:1153-8. doi: 10.1161/ATVBAHA.106.136325

83. Weichhart T, Kopecky C, Kubicek M, Haidinger M, Doller D, Katholnig K, et al. Serum amyloid A in uremic HDL promotes inflammation. J Am Soc Nephrol. (2012) 23:934-47. doi: 10.1681/ASN.2011070668

84. Ansell BJ, Navab M, Hama S, Kamranpour N, Fonarow G, Hough $\mathrm{G}$, et al. Inflammatory/antiinflammatory properties of highdensity lipoprotein distinguish patients from control subjects better than high-density lipoprotein cholesterol levels and are favorably affected by simvastatin treatment. Circulation. (2003) 108:2751-6. doi: 10.1161/01.CIR.0000103624.14436.4B

85. Ansell BJ, Fonarow GC Fogelman AM. The paradox of dysfunctional high-density lipoprotein. Curr Opin Lipidol. (2007) 18:427-34. doi: 10.1097/MOL.0b013e3282364a17

86. Szeto CC, Kwan BC, Chow KM, Lai KB, Chung KY, Leung CB, et al. Endotoxemia is related to systemic inflammation and atherosclerosis 
in peritoneal dialysis patients. Clin J Am Soc Nephrol. (2008) 3:4316. doi: $10.2215 / \mathrm{CJN} .03600807$

87. Kho ZY Lal SK. The human gut microbiome - a potential controller of wellness and disease. Front Microbiol. (2018) 9:1835. doi: 10.3389/fmicb.2018.01835

88. Schefold JC, Zeden JP, Fotopoulou C, von Haehling S, Pschowski R, Hasper D, et al. Increased indoleamine 2,3-dioxygenase (IDO) activity and elevated serum levels of tryptophan catabolites in patients with chronic kidney disease: a possible link between chronic inflammation and uraemic symptoms. Nephrol Dial Transplant. (2009) 24:19018. doi: 10.1093/ndt/gfn739

89. Bruce MA, Griffith DM, Thorpe RJ. Stress and the kidney. Adv Chronic Kidney Dis. (2015) 22:46-53. doi: 10.1053/j.ackd.2014.06.008

90. Baragetti I, El Essawy B Fiorina P. Targeting immunity in end-stage renal disease. Am J Nephrol. (2017) 45:310-9. doi: 10.1159/000458768

91. Steven S, Frenis K, Oelze M, Kalinovic S, Kuntic M, Bayo Jimenez MT, et al. Vascular inflammation and oxidative stress: major triggers for cardiovascular disease. Oxid Med Cell Longev. (2019) 2019:7092151. doi: 10.1155/2019/7092151

92. Munoz-Durango N, Fuentes CA, Castillo AE, Gonzalez-Gomez LM, Vecchiola A, Fardella CE, et al. Role of the renin-angiotensin-aldosterone system beyond blood pressure regulation: molecular and cellular mechanisms involved in end-organ damage during arterial hypertension. Int J Mol Sci. (2016) 17:797. doi: 10.3390/ijms17070797

93. Thethi T, Kamiyama M Kobori H. The link between the renin-angiotensinaldosterone system and renal injury in obesity and the metabolic syndrome. Curr Hypertens Rep. (2012) 14:160-9. doi: 10.1007/s11906-012-0245-Z

94. Ingraham NE, Barakat $A G$, Reilkoff $R$, Bezdicek $T$, Schacker $T$, Chipman JG, et al. Understanding the renin-angiotensin-aldosteroneSARS-CoV axis: a comprehensive review. Eur Respir J. (2020) 56:2000912. doi: 10.1183/13993003.00912-2020

95. Stas S, Whaley-Connell A, Habibi J, Appesh L, Hayden MR, Karuparthi PR, et al. Mineralocorticoid receptor blockade attenuates chronic overexpression of the renin-angiotensin-aldosterone system stimulation of reduced nicotinamide adenine dinucleotide phosphate oxidase and cardiac remodeling. Endocrinology. (2007) 148:3773-80. doi: 10.1210/en.2006-1691

96. Bochud M, Nussberger J, Bovet P, Maillard MR, Elston RC, Paccaud F, et al. Plasma aldosterone is independently associated with the metabolic syndrome. Hypertension. (2006) 48:239-45. doi: 10.1161/01.HYP.0000231338.41548.fc

97. Engeli S, Schling P, Gorzelniak K, Boschmann M, Janke J, Ailhaud $\mathrm{G}$, et al. The adipose-tissue renin-angiotensin-aldosterone system: role in the metabolic syndrome? Int J Biochem Cell Biol. (2003) 35:80725. doi: 10.1016/S1357-2725(02)00311-4

98. Massiera F, Seydoux J, Geloen A, Quignard-Boulange A, Turban S, Saint-Marc P, et al. Angiotensinogen-deficient mice exhibit impairment of diet-induced weight gain with alteration in adipose tissue development and increased locomotor activity. Endocrinology. (2001) 142:5220-5. doi: 10.1210/endo.142.12.8556

99. Kobori H, Urushihara M, Xu JH, Berenson GS, Navar LG. Urinary angiotensinogen is correlated with blood pressure in men (bogalusa heart study). J Hypertens. (2010) 28:1422-8. doi: 10.1097/HJH.0b013e32833 92673

100. Weisinger JR, Kempson RL, Eldridge FL Swenson RS. The nephrotic syndrome: a complication of massive obesity. Ann Intern Med. (1974) 81:440-7. doi: 10.7326/0003-4819-81-4-440

101. Chagnac A, Herman M, Zingerman B, Erman A, Rozen-Zvi B, Hirsh J, et al. Obesity-induced glomerular hyperfiltration: its involvement in the pathogenesis of tubular sodium reabsorption. Nephrol Dial Transplant. (2008) 23:3946-52. doi: 10.1093/ndt/gfn379

102. Wuerzner G, Pruijm M, Maillard M, Bovet P, Renaud C, Burnier M, et al. Marked association between obesity and glomerular hyperfiltration: a cross-sectional study in an African population. Am J Kidney Dis. (2010) 56:303-12. doi: 10.1053/j.ajkd.2010.03.017

103. Chagnac A, Weinstein T, Herman M, Hirsh J, Gafter U, Ori Y. The effects of weight loss on renal function in patients with severe obesity. J Am Soc Nephrol. (2003) 14:1480-6. doi: 10.1097/01.ASN.0000068462.38 661.89
104. Must A, Spadano J, Coakley EH, Field AE, Colditz G Dietz WH. The disease burden associated with overweight and obesity. JAMA. (1999) 282:15239. doi: $10.1001 /$ jama.282.16.1523

105. Chagnac A, Weinstein T, Korzets A, Ramadan E, Hirsch J Gafter U. Glomerular hemodynamics in severe obesity. Am J Physiol Renal Physiol. (2000) 278:F817-22. doi: 10.1152/ajprenal.2000.278.5.F817

106. Kambham N, Markowitz GS, Valeri AM, Lin J D'Agati VD. Obesityrelated glomerulopathy: an emerging epidemic. Kidney Int. (2001) 59:1498509. doi: 10.1046/j.1523-1755.2001.0590041498.x

107. Praga M, Hernandez E, Morales E, Campos AP, Valero MA, Martinez MA, et al. Clinical features and long-term outcome of obesity-associated focal segmental glomerulosclerosis. Nephrol Dial Transplant. (2001) 16:1790-8. 10. doi: $10.1093 / \mathrm{ndt} / 16.9 .1790$

108. Mallamaci F, Ruggenenti P, Perna A, Leonardis D, Tripepi R, Tripepi G, et al. ACE inhibition is renoprotective among obese patients with proteinuria. J Am Soc Nephrol. (2011) 22:1122-8. doi: 10.1681/ASN.2010090969

109. Vejakama P, Ingsathit A, McKay GJ, Maxwell AP, McEvoy M, Attia J, et al. Treatment effects of renin-angiotensin aldosterone system blockade on kidney failure and mortality in chronic kidney disease patients. $B M C$ Nephrol. (2017) 18:342. doi: 10.1186/s12882-017-0753-9

110. Tsuboi N, Utsunomiya Y, Kanzaki G, Koike K, Ikegami M, Kawamura $\mathrm{T}$, et al. Low glomerular density with glomerulomegaly in obesity-related glomerulopathy. Clin J Am Soc Nephrol. (2012) 7:735-41. doi: 10.2215/CJN.07270711

111. Garg R Adler GK. Aldosterone and the mineralocorticoid receptor: risk factors for cardiometabolic disorders. Curr Hypertens Rep. (2015) 17:52. doi: 10.1007/s11906-015-0567-8

112. Barrera-Chimal J, Girerd S Jaisser F. Mineralocorticoid receptor antagonists and kidney diseases: pathophysiological basis. Kidney Int. (2019) 96:30219. doi: 10.1016/j.kint.2019.02.030

113. Bomback AS, Muskala P, Bald E, Chwatko G Nowicki M. Lowdose spironolactone, added to long-term ACE inhibitor therapy, reduces blood pressure and urinary albumin excretion in obese patients with hypertensive target organ damage. Clin Nephrol. (2009) 72:449-56. doi: 10.5414/CNP72449

114. Toto RD. Aldosterone blockade in chronic kidney disease: can it improve outcome? Curr Opin Nephrol Hypertens. (2010) 19:444-9. doi: 10.1097/MNH.0b013e32833ce6d5

115. Haller H, Bertram A, Stahl K Menne J. Finerenone: a new mineralocorticoid receptor antagonist without hyperkalemia: an opportunity in patients with CKD? Curr Hypertens Rep. (2016) 18:41. doi: 10.1007/s11906-016-0649-2

116. Straznicky NE, Grima MT, Lambert EA, Eikelis N, Dawood T, Lambert GW, et al. Exercise augments weight loss induced improvement in renal function in obese metabolic syndrome individuals. J Hypertens. (2011) 29:553-64. doi: 10.1097/HJH.0b013e3283418875

117. Friedman AN, Chambers M, Kamendulis LM Temmerman J. Short-term changes after a weight reduction intervention in advanced diabetic nephropathy. Clin J Am Soc Nephrol. (2013) 8:1892-8. doi: 10.2215/CJN.04010413

118. Morales E, Valero MA, Leon M, Hernandez E Praga M. Beneficial effects of weight loss in overweight patients with chronic proteinuric nephropathies. Am J Kidney Dis. (2003) 41:319-27. doi: 10.1053/ajkd.2003.50039

119. Navaneethan SD, Yehnert H, Moustarah F, Schreiber MJ, Schauer PR Beddhu S. Weight loss interventions in chronic kidney disease: a systematic review and meta-analysis. Clin J Am Soc Nephrol. (2009) 4:156574. doi: 10.2215/CJN.02250409

120. Shen WW, Chen HM, Chen H, Xu F, Li LS Liu ZH. Obesity-related glomerulopathy: body mass index and proteinuria. Clin J Am Soc Nephrol. (2010) 5:1401-9. doi: 10.2215/CJN.01370210

121. Joris PJ, Plat J, Kusters YH, Houben AJ, Stehouwer CD, Schalkwijk $\mathrm{CG}$, et al. Diet-induced weight loss improves not only cardiometabolic risk markers but also markers of vascular function: a randomized controlled trial in abdominally obese men. Am J Clin Nutr. (2017) 105:2331. doi: 10.3945/ajcn.116.143552

122. Kassem MA, Durda MA, Stoicea N, Cavus O, Sahin L Rogers B. The impact of bariatric surgery on type 2 diabetes mellitus and the management of hypoglycemic events. Front Endocrinol. (2017) 8:37. doi: $10.3389 /$ fendo.2017.00037 
123. Ritz E. Bariatric surgery and the kidney-much benefit, but also potential harm. Clin Kidney J. (2013) 6:368-72. doi: 10.1093/ckj/sfs161

124. Bellini MI, Paoletti F Herbert PE. Obesity and bariatric intervention in patients with chronic renal disease. J Int Med Res. (2019) 47:23262341. doi: $10.1177 / 0300060519843755$

125. Friedman AN. The case for a bariatric-centered approach to CKD care. Clin J Am Soc Nephrol. (2019) 14:291-3. doi: 10.2215/CJN.12061018

126. Nehus EJ, Khoury JC, Inge TH, Xiao N, Jenkins TM, Moxey-Mims MM, et al. Kidney outcomes three years after bariatric surgery in severely obese adolescents. Kidney Int. (2017) 91:451-8. doi: 10.1016/j.kint.2016.09.031

127. Chang AR, Grams ME Navaneethan SD. Bariatric surgery and kidney-related outcomes. Kidney Int Rep. (2017) 2:261-70. doi: 10.1016/j.ekir.2017.01.010

128. Turgeon NA, Perez S, Mondestin M, Davis SS, Lin E, Tata S, et al. The impact of renal function on outcomes of bariatric surgery. J Am Soc Nephrol. (2012) 23:885-94. doi: 10.1681/ASN.2011050476

129. Chamberlain JJ, Herman WH, Leal S, Rhinehart AS, Shubrook JH, Skolnik $\mathrm{N}$, et al. Pharmacologic therapy for type 2 diabetes: synopsis of the 2017 American diabetes association standards of medical care in diabetes. Ann Intern Med. (2017) 166:572-8. doi: 10.7326/M16-2937

130. Greco EV, Russo G, Giandalia A, Viazzi F, Pontremoli R De Cosmo S. GLP-1 receptor agonists and kidney protection. Medicina. (2019) 55:233. doi: 10.3390/medicina55060233

131. Sheu WHH, Chan SP, Matawaran BJ, Deerochanawong C, Mithal A, Chan J, et al. Use of SGLT-2 inhibitors in patients with type 2 diabetes mellitus and abdominal obesity: an Asian perspective and expert recommendations. Diabetes Metab J. (2020) 44:11-32. doi: 10.4093/dmj.2019.0208

132. Thornton SN, Regnault V Lacolley P. Liraglutide and renal outcomes in type 2 diabetes. N Engl J Med. (2017) 377:2196-7. doi: 10.1056/NEJMc1713042

133. Tuttle KR, Lakshmanan MC, Rayner B, Busch RS, Zimmermann AG, Woodward DB, et al. Dulaglutide versus insulin glargine in patients with type 2 diabetes and moderate-to-severe chronic kidney disease (AWARD7): a multicentre, open-label, randomised trial. Lancet Diabetes Endocrinol. (2018) 6:605-17. doi: 10.1016/S2213-8587(18)30104-9

134. Musso G, Gambino R, Cassader M Pagano G. A novel approach to control hyperglycemia in type 2 diabetes: sodium glucose co-transport (SGLT) inhibitors: systematic review and meta-analysis of randomized trials. Ann Med. (2012) 44:375-93. doi: 10.3109/07853890.2011.560181

135. Pereira MJ Eriksson JW. Emerging role of SGLT-2 inhibitors for the treatment of obesity. Drugs. (2019) 79:21930. doi: 10.1007/s40265-019-1057-0

136. Frias JP, Guja C, Hardy E, Ahmed A, Dong F, Ohman P, et al. Exenatide once weekly plus dapagliflozin once daily versus exenatide or dapagliflozin alone in patients with type 2 diabetes inadequately controlled with metformin monotherapy (DURATION-8): a 28 week, multicentre, double-blind, phase 3, randomised controlled trial. Lancet Diabetes Endocrinol. (2016) 4:100416. doi: 10.1016/S2213-8587(16)30267-4

137. Seidu S, Kunutsor SK, Cos X, Gillani S, Khunti K, For, et al. SGLT2 inhibitors and renal outcomes in type 2 diabetes with or without renal impairment: A systematic review and meta-analysis. Prim Care Diabetes. (2018) 12:265283. doi: 10.1016/j.pcd.2018.02.001

138. Dorotea D, Koya D Ha H. Recent insights into SREBP as a direct mediator of kidney fibrosis via lipid-independent pathways. Front Pharmacol. (2020) 11:265. doi: 10.3389/fphar.2020.00265

139. Han CY. Update on FXR biology: promising therapeutic target? Int J Mol Sci. (2018) 19:2069. doi: 10.3390/ijms19072069

140. Zhang Y, Ma KL, Liu J, Wu Y, Hu ZB, Liu L, et al. Dysregulation of low-density lipoprotein receptor contributes to podocyte injuries in diabetic nephropathy. Am J Physiol Endocrinol Metab. (2015) 308:E11408. doi: 10.1152/ajpendo.00591.2014

141. Tanaka Y, Kume S, Araki S, Isshiki K, Chin-Kanasaki M, Sakaguchi $\mathrm{M}$, et al. Fenofibrate, a PPARalpha agonist, has renoprotective effects in mice by enhancing renal lipolysis. Kidney Int. (2011) 79:87182. doi: 10.1038/ki.2010.530

142. Hong YA, Lim JH, Kim MY, Kim TW, Kim Y, Yang KS, et al. Fenofibrate improves renal lipotoxicity through activation of AMPK-PGC-1alpha in db/db mice. PLoS ONE. (2014) 9:e96147. doi: 10.1371/journal.pone.0096147

143. Tsai HC, Chang FP, Li TH, Liu CW, Huang CC, Huang SF, et al. Elafibranor inhibits chronic kidney disease progression in NASH mice. Biomed Res Int. (2019) 2019:6740616. doi: 10.1155/2019/6740616

144. Kratzer A, Buchebner M, Pfeifer T, Becker TM, Uray G, Miyazaki M, et al. Synthetic LXR agonist attenuates plaque formation in apoE-/- mice without inducing liver steatosis and hypertriglyceridemia. J Lipid Res. (2009) 50:312-26. doi: 10.1194/jlr.M800376-JLR200

145. Calkin AC Tontonoz P. Transcriptional integration of metabolism by the nuclear sterol-activated receptors LXR and FXR. Nat Rev Mol Cell Biol. (2012) 13:213-24. doi: 10.1038/nrm3312

146. Wu J, Zhang Y, Wang N, Davis L, Yang G, Wang X, et al. Liver X receptoralpha mediates cholesterol efflux in glomerular mesangial cells. Am J Physiol Renal Physiol. (2004) 287:F886-95. doi: 10.1152/ajprenal.00123.2004

147. Herman-Edelstein M, Scherzer P, Tobar A, Levi M, Gafter U. Altered renal lipid metabolism and renal lipid accumulation in human diabetic nephropathy. J Lipid Res. (2014) 55:561-72. doi: 10.1194/jlr.P0 40501

148. Wang Y, Moser AH, Shigenaga JK, Grunfeld C Feingold KR. Downregulation of liver $\mathrm{X}$ receptor-alpha in mouse kidney and HK2 proximal tubular cells by LPS and cytokines. J Lipid Res. (2005) 46:2377-87. doi: 10.1194/jlr.M500134-JLR200

149. Tachibana H, Ogawa D, Matsushita Y, Bruemmer D, Wada J, Teshigawara $\mathrm{S}$, et al. Activation of liver $\mathrm{X}$ receptor inhibits osteopontin and ameliorates diabetic nephropathy. J Am Soc Nephrol. (2012) 23:183546. doi: 10.1681/ASN.2012010022

150. Patel M, Wang XX, Magomedova L, John R, Rasheed A, Santamaria $H$, et al. Liver $X$ receptors preserve renal glomerular integrity under normoglycaemia and in diabetes in mice. Diabetologia. (2014) 57:43546. doi: 10.1007/s00125-013-3095-6

151. Kuipers I, van der Harst P, Kuipers F, van Genne L, Goris M, Lehtonen JY, et al. Activation of liver $\mathrm{X}$ receptor-alpha reduces activation of the renal and cardiac renin-angiotensin-aldosterone system. Lab Invest. (2010) 90:630-6. doi: 10.1038/labinvest.2010.7

152. Soodvilai S, Jia Z, Fongsupa S, Chatsudthipong V, Yang T. Liver $\mathrm{X}$ receptor agonists decrease ENaC-mediated sodium transport in collecting duct cells. Am J Physiol Renal Physiol. (2012) 303:F1610-6. doi: 10.1152/ajprenal.00283.2012

153. Raksaseri P, Chatsudthipong V, Muanprasat C, Soodvilai S. Activation of liver X receptors reduces CFTR-mediated $\mathrm{Cl}(-)$ transport in kidney collecting duct cells. Am J Physiol Renal Physiol. (2013) 305:F58391. doi: 10.1152/ajprenal.00579.2012

154. Merscher-Gomez S, Guzman J, Pedigo CE, Lehto M, Aguillon-Prada R, Mendez A, et al. Cyclodextrin protects podocytes in diabetic kidney disease. Diabetes. (2013) 62:3817-27. doi: 10.2337/db13-0399

Conflict of Interest: The authors declare that the research was conducted in the absence of any commercial or financial relationships that could be construed as a potential conflict of interest.

Copyright (C) 2021 Sharma, Liao, Zheng and Kanwar. This is an open-access article distributed under the terms of the Creative Commons Attribution License (CC BY). The use, distribution or reproduction in other forums is permitted, provided the original author(s) and the copyright owner(s) are credited and that the original publication in this journal is cited, in accordance with accepted academic practice. No use, distribution or reproduction is permitted which does not comply with these terms. 